ARTICLE

Received 18 Jan 2012 | Accepted 15 Jan 2013 | Published 19 Feb 2013 DOI: 10.1038/ncomms2490

\title{
Ion-association complexes unite classical and non-classical theories for the biomimetic nucleation of calcium phosphate
}

Wouter J.E.M. Habraken ${ }^{1,2}$, Jinhui Tao ${ }^{3}$, Laura J. Brylka1', Heiner Friedrich'1, Luca Bertinetti², Anna S. Schenk ${ }^{2}$, Andreas Verch4, Vladimir Dmitrovic ${ }^{1}$, Paul H.H. Bomans', Peter M. Frederik1, Jozua Laven', Paul van der Schoot $^{5}$, Barbara Aichmayer ${ }^{2}$, Gijsbertus de With', James J. DeYoreo ${ }^{3}$ \& Nico A.J.M. Sommerdijk ${ }^{1}$

Despite its importance in many industrial, geological and biological processes, the mechanism of crystallization from supersaturated solutions remains a matter of debate. Recent discoveries show that in many solution systems nanometre-sized structural units are already present before nucleation. Still little is known about the structure and role of these so-called pre-nucleation clusters. Here we present a combination of in situ investigations, which show that for the crystallization of calcium phosphate these nanometre-sized units are in fact calcium triphosphate complexes. Under conditions in which apatite forms from an amorphous calcium phosphate precursor, these complexes aggregate and take up an extra calcium ion to form amorphous calcium phosphate, which is a fractal of $\mathrm{Ca}_{2}\left(\mathrm{HPO}_{4}\right)_{3}^{2}-$ clusters. The calcium triphosphate complex also forms the basis of the crystal structure of octacalcium phosphate and apatite. Finally, we demonstrate how the existence of these complexes lowers the energy barrier to nucleation and unites classical and non-classical nucleation theories.

\footnotetext{
${ }^{1}$ Eindhoven University of Technology, Department of Chemical Engineering and Chemistry, Laboratory of Materials and Interface Chemistry and Soft Matter Cryo-TEM Research Unit, PO Box 513, 5600 MB Eindhoven, The Netherlands. ${ }^{2}$ Max Planck Institute of Colloids and Interfaces, Department of Biomaterials, Research Campus Golm, 14424 Potsdam, Germany. ${ }^{3}$ Molecular Foundry, Lawrence Berkeley Laboratory, Berkeley, California 94720, USA. ${ }^{4}$ Max Planck Institute of Colloids and Interfaces, Department of Colloid Chemistry, Research Campus Golm, 14424 Potsdam, Germany. ${ }^{5}$ Eindhoven University of Technology, Group Theory of Polymers and Soft Matter, Department of Applied Physics, PO Box 513, 5600 MB Eindhoven, The Netherlands. Correspondence and requests for materials should be addressed to J.J.D. (email: James.DeYoreo@pnnl.gov) or to N.A.J.M.S. (email: N.Sommerdijk@tue.nl).
} 
A ccording to Classical Nucleation Theory ${ }^{1,2}$, the first step in the formation of crystalline mineral phases involves the stochastic and dynamic association of ions in solution, overcoming a free-energy barrier to form nuclei that, above a critical size, can grow out to a mature crystal. In addition, the rate equations that derive from this theory show that the first material to precipitate is not necessarily the thermodynamically most stable state, but the kinetically most accessible one, which may later transform into the thermodynamically more stable form. The appearance of amorphous precursors, which are observed for many minerals ${ }^{3}$, fits this concept of multistage crystallization ${ }^{4}$ that was first put forth by Ostwald and later revised to incorporate the evolution in the understanding of both thermodynamic and kinetic factors ${ }^{5}$. One example of such a mineral is calcium phosphate, the main component of bone and tooth and consequently the most studied biomineral, with major applications in dentistry, orthopaedics and reconstructive surgery ${ }^{6}$.

Biological calcium phosphate is rather ill-defined, best described as poorly crystalline, highly substituted apatite (AP) ${ }^{7}$ and has recently been demonstrated to form via an amorphous precursor phase ${ }^{8-10}$. Already in the $1960 \mathrm{~s}$, biomimetic mineralization experiments were directed at understanding the formation mechanism of this mineral, and resulted in the precipitation of calcium phosphate with X-ray diffraction characteristics identical to those of the biological material ${ }^{11}$. These early investigations indicated the presence of a metastable amorphous precursor phase, which was postulated to consist $\mathrm{Ca}_{9}\left(\mathrm{PO}_{4}\right)_{6}$ clusters ${ }^{12}$. Although initially these observations were met with skepticism ${ }^{13}$, recently reports confirmed that the precipitation of calcium phosphate indeed involves the formation of nanometre-sized building blocks ${ }^{14-18}$. In fact for many different organic ${ }^{19,20}$ and inorganic crystals $^{3,18,21}$, nucleation models involving pre-nucleation clusters have been proposed. However, owing to their small dimensions, it has so far not been possible to unravel the structural details of the clusters in their native hydrated state nor of the mechanism by which they aggregate. Moreover, the impact of such clusters on the energy barriers that ultimately dictate passage through the amorphous phase has not yet been fully explored $^{22}$.

Here, we study the biomimetic precipitation of calcium phosphate, in a buffered solution and under constant ionic strength, where a wide range of in situ analysis techniques provide morphological, structural and chemical information. These experiments reveal that the formerly observed calcium phosphate pre-nucleation clusters in fact are calcium triphosphate ion-association complexes, which can aggregate into branched three-dimensional (3D) polymeric structures. From these polymeric solution structures, nucleation of amorphous calcium phosphate (ACP) occurs through the simultaneous binding of calcium to form $\sim 1.2 \mathrm{~nm}$ post-nucleation clusters, and their aggregation and precipitation as spherical particles. Continued calcium uptake converts ACP into octacalcium phosphate (OCP) and subsequently into AP, which both contain the calcium triphosphate complex as their basic structural unit. Measuring the rate of calcium phosphate nucleation as a function of supersaturation, we show that under the conditions used here, ACP formation cannot be directly reconciled with classical nucleation theory. However, theoretical considerations show that the thermodynamic barrier for nucleation is dramatically lowered when the existence of pre-nucleation complexes and the particle size dependence of the interfacial free energy are taken into account. With this, the observed non-classical route to ACP formation can be explained using classical theory.

\section{Results}

Morphological development during calcium phosphate formation. Biomimetic calcium phosphate was prepared by the instantaneous addition of a phosphate solution to a gently stirred solution of calcium ions. During the reaction, samples were collected and vitrified on electron microscope grids for high-resolution cryogenic transmission electron microscopy (cryo-TEM) analysis $^{21}$. Cryo-TEM images (Fig. 1a-i) showed that the growth of calcium phosphate proceeds via multiple distinct morphologies. Within the first minutes after the addition, strands of nanometre-sized units-not seen in the buffers themselves (Supplementary Fig. S8D)-appeared in the solution (Fig. 1a), and grew out to form a branched polymeric network (Fig. 1b) that subsequently developed nodules (Fig. 1c) with dimensions of $150-200 \mathrm{~nm}$. In agreement with previous reports ${ }^{14,23-25}$, these nodules condensed further, transforming into spheres that coagulated and subsequently precipitated after 15-20 min (Fig. 1d). This sequence of events was supported by dynamic light scattering data (Supplementary Fig. S1). Highresolution cryo-TEM revealed that also the spheres consisted of nanometre-sized building blocks. After $\sim 1 \mathrm{~h}$ the coagulated spheres transformed, producing a thin ribbon-like morphology (Fig. 1e,f). At this time, a small number of polymeric chains were still present inside the solution, and occasionally the direct assembly of ribbons from these polymers was observed (Fig. 1g). In time, the ribbons evolved into their final shape that consists of elongated plates (Fig. 1h,i), similar to the morphology as described for biomimetic $\mathrm{AP}^{26}$.

The evolution of structure. During the reaction both the calcium concentration $\left(\left[\mathrm{Ca}^{2+}\right]\right)$ and the $\mathrm{pH}$ were monitored, revealing that the morphological transitions observed with cryo-TEM corresponded to distinct, concomitant drops in the free $\left[\mathrm{Ca}^{2+}\right]$ and $\mathrm{pH}$ (Fig. 2a). This implies that each of the four subsequent morphologies (polymeric aggregates, spheres, ribbons and elongated plates) represents a separate phase with its own characteristic calcium solubility. As no changes in the free $\left[\mathrm{Ca}^{2+}\right]$ or $\mathrm{pH}$ occur during the first minutes of the reaction (see also Supplementary Fig. S2), we must consider the first drop in $\left[\mathrm{Ca}^{2+}\right]$ or $\mathrm{pH}$ as the nucleation point, that is, the point where the first new phase appears from solution. Hence, we consider the polymeric network of nanometre-sized units found before the first phase transition as pre-nucleation species, and the spherical aggregates of nanometre-sized building blocks after this transition as post-nucleation species. The nodules consequently present a transition state at which both the chemical transformation and the aggregation are only partially completed.

In agreement with previous reports ${ }^{14,15}$, low-dose selected area electron diffraction (LDSAED, Fig. 3a) demonstrated that both in the pre-nucleation and the post-nucleation stage no (long-range) structural order was present, characterizing the precipitate of coagulated spherical aggregates as ACP. Analysis of the third phase (ribbons) revealed the appearance of a broad band at a lattice spacing $(d)$ of $0.26-0.33 \mathrm{~nm}$ that became more pronounced in the fourth phase (plates).

Wide-angle synchrotron X-ray scattering (WAXS) measurements (Fig. 4a) on samples of this stage gave proof of a structure very similar to OCP. Only the (100) peak, which corresponds to planes with a large $d$-spacing of $1.85 \mathrm{~nm}$ along the thinnest dimension of the OCP plate-like morphology ${ }^{27}$, was missing. This can be explained by the small thickness of the OCPlike plates in our samples $(\approx 1.4 \mathrm{~nm}$, see small-angle synchrotron $\mathrm{X}$-ray scattering (SAXS) data Fig. 4b), which is less than the $d$-spacing between the (100) planes in OCP crystals. LDSAED from plates aged for 1 month revealed a peak at $d=0.28 \mathrm{~nm}$ 

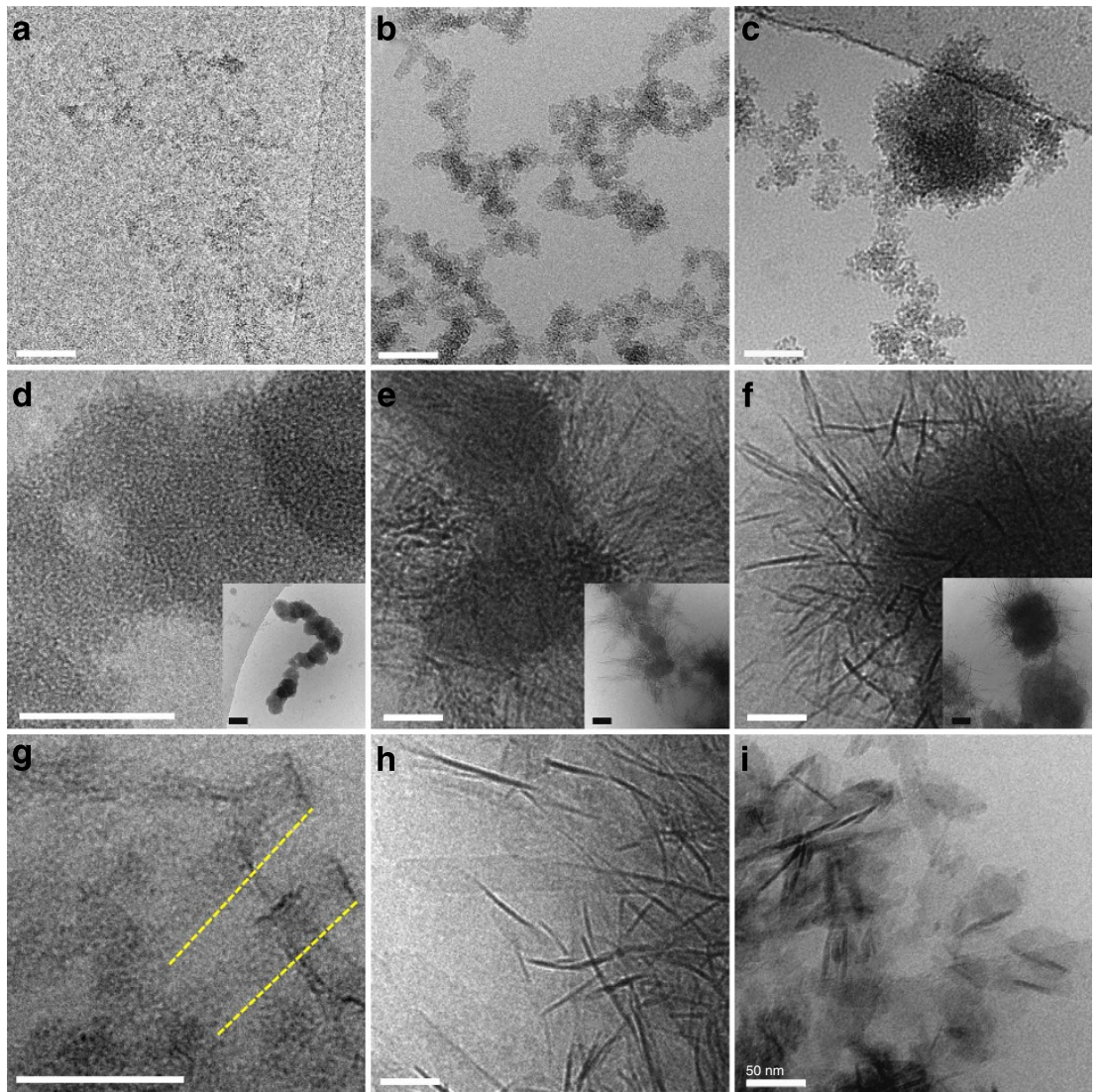

Figure 1 | Morphological transformations of CaP during time as observed by Cryo-TEM. (a) Polymeric strands from nanometre-sized units ( $<2$ min), (b) branched polymeric assemblies (2-20 min), (c) nodules $(10-20 \mathrm{~min}),(\mathbf{d})$ aggregated spheres (15-60 min), (e) aggregated spheres + ribbons (60-80 $\mathrm{min})$, (f) ribbons (80-110 min), (g) direct assembly of ribbons from polymeric aggregates (60-110 min) (lines denote alignment of complexes), (h) elongated plates ( $>110 \mathrm{~min}$ ), (i) plates (1 month), scale bar, $50 \mathrm{~nm}$ (insets are lower magnification images: scale bar, $100 \mathrm{~nm}$ ). Similar morphological transformations were found in solutions without Tris-buffer (see Supplementary Fig. S13).

corresponding to the (211)/(112) planes of AP (Fig. 3a), implicating that, as in previous reports $23,24,28-31$, the OCP-like structure acted as a precursor for AP. These structural developments were supported by in situ Fourier transform infrared spectroscopy (FTIR, Fig. 3b), which further indicated significant chemical transformations between the different morphological stages.

Chemical development through calcium binding. By monitoring the $\mathrm{pH}$ and the free $\left[\mathrm{Ca}^{2+}\right]$, the release of protons and the changes in the concentration of bound calcium could be determined (Fig. 2b). From these data and taking into account the applied physicochemical conditions and the relevant chemical equilibria (see also Supplementary Methods), we calculated the concentration of the different calcium-bound phosphate species $\left(\mathrm{H}_{2} \mathrm{PO}_{4}^{-}, \mathrm{HPO}_{4}^{2-}\right.$ and $\left.\mathrm{PO}_{4}^{3-}\right)$ in the subsequent stages of the reaction (Fig. 2c). Combining the information on the calcium and phosphate concentrations at different time points, and taking into account that also calcium phosphate ion pairs are formed, the calcium/phosphate $(\mathrm{Ca} / \mathrm{P})$ ratios of the different phases were calculated (Fig. 2d). In addition, also their formal charges (Fig. 2e) and compositions were derived (see also Supplementary Table $\mathrm{S} 1)$. For the pre-nucleation species $(\mathrm{Ca} / \mathrm{P}=0.3-0.4)$, this yielded an ion-association complex with the formula $\left[\mathrm{Ca}\left(\mathrm{HPO}_{4}\right)_{3}\right]^{4-}$ of which $57 \%$ was in its protonated state $\left[\mathrm{Ca}\left(\mathrm{HPO}_{4}\right)_{2}\left(\mathrm{H}_{2} \mathrm{PO}_{4}\right)\right]^{3-}$.

To determine the exact speciation of the pre-nucleation complex chemistry, a titration ${ }^{18}$ and a dilution experiment were performed. Upon titrating small $\mathrm{Ca}^{2+}$-containing aliquots to a high phosphate concentration $([\mathrm{P}])$, a constant ratio of free to bound $\mathrm{Ca}^{2}+$ was measured during the first $20 \mathrm{~min}$ (Supplementary Fig. S4). As initially $[\mathrm{P}]$ is approximately constant, the concentration of all pre-nucleation species (both complexes and ion pairs) according to the overall equilibrium in the pre-nucleation stage (Fig. 5a) is independent of $[\mathrm{P}]$, that is: $K_{\text {eq }} \propto\left[\right.$ pre-nucleation species] $/\left[\mathrm{Ca}^{2+}\right]^{x}=\left[\mathrm{Ca}_{x}\left(\mathrm{HPO}_{4}\right)_{y}\right.$ $\left.\left(\mathrm{H}_{2} \mathrm{PO}_{4}\right)_{z}^{2 x-2 y-z}\right] /\left[\mathrm{Ca}^{2+}\right]^{x}$ with $x$ being the number of $\mathrm{Ca}^{2+}$ ions inside a pre-nucleation species and $K_{\text {eq }}$ the equilibrium constant of the pre-nucleation species. In the pre-nucleation stage, all bound calcium must be present either as complexes or ion pairs. A constant ratio of free to bound $\mathrm{Ca}^{2+}$ therefore implies $x=1$, and hence that all pre-nucleation species contain only one calcium ion (see Supplementary Methods: titration experiment).

By subsequently monitoring $\left[\mathrm{Ca}^{2+}\right]$ upon dilution of the prenucleation stage-with all equilibrium constants of all prenucleation species remaining unchanged-the composition of the pre-nucleation species could be calculated (see Supplementary Methods: dilution experiment). This revealed a dynamic equilibrium between pre-nucleation complexes with ions and ion pairs (mainly $\mathrm{CaHPO}_{4}$ ) in solution according to the reaction scheme presented in Fig. 5b.

For these pre-nucleation complexes, $a b$ initio calculations indicated a triangular arrangement of phosphates around the calcium ion. This results in a disc-like shape with a diameter of $1.1 \mathrm{~nm}$ and a height of $0.5 \mathrm{~nm}$ (Fig. 5c,d, Supplementary Fig. S7). 

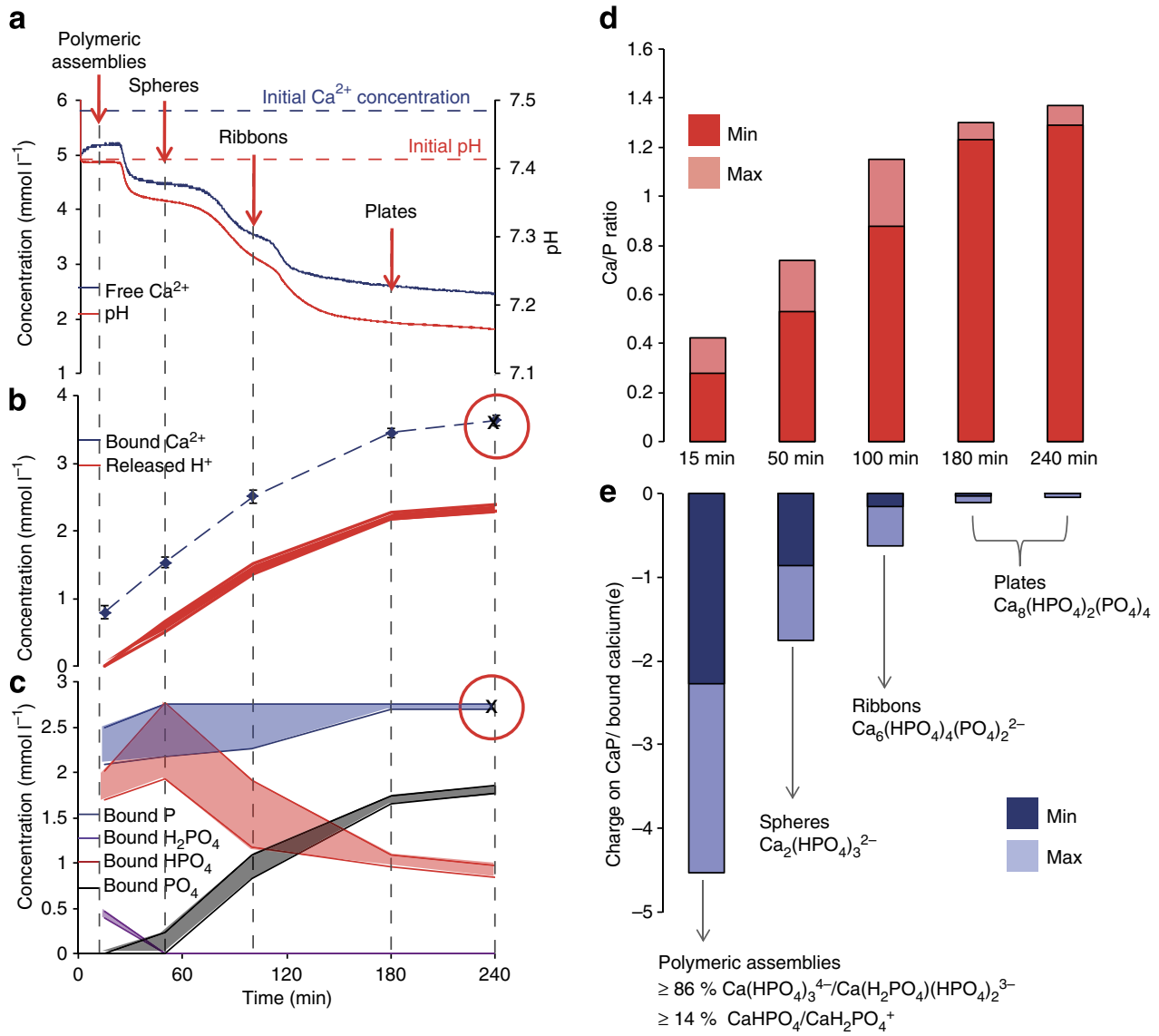

Figure 2 | Chemistry of the bound calcium phosphate at the different stages. (a) Free $\mathrm{Ca}^{2}+$ concentration and $\mathrm{pH}$ as measured, (b) derived concentration of bound $\mathrm{Ca}^{2+}$ and calculated range of released $\mathrm{H}^{+},(\mathbf{c})$ calculated concentrations of bound phosphate $\mathrm{P}$ and its components $\left(\mathrm{H}_{2} \mathrm{PO}_{4}^{-}, \mathrm{HPO}_{4}^{2-}, \mathrm{PO}_{4}^{3-}\right)$, (d) $\mathrm{Ca} / \mathrm{P}$ ratio, (e) charge on calcium phosphate, expressed in number of elementary charges/bound $\mathrm{Ca}^{2+}$ and calculated chemical compositions of the different phases. ICP-OES measurements of $\mathrm{Ca}^{2+}$ and $\mathrm{P}$ are indicated by the markers $(\mathrm{X})$ in $(\mathbf{b})$ and $(\mathbf{c})$. Error bars are s.e.'s over an average of eight experiments. (c) Shows an initial increase in the concentration of bound $\mathrm{HPO}_{4}^{2-}$, owing to the consumption of $\mathrm{H}_{2} \mathrm{PO}_{4}^{-}$during the first phase transition. In the subsequent steps, the concentration of bound $\mathrm{HPO}_{4}^{2-}$ decreased again, in favour of the formation of $\mathrm{PO}_{4}^{3-}$, as was also indicated by FTIR (Fig. 3b). Average chemistries for the phosphate species at different stages correspond to polymeric assemblies $(15 \mathrm{~min}): \geq 86 \% \mathrm{Ca}\left(\mathrm{HPO}_{4}\right)_{3}^{4-} / \mathrm{Ca}\left(\mathrm{HPO}_{4}\right)_{2}\left(\mathrm{H}_{2} \mathrm{PO}_{4}\right)^{3-}$ and $\leq 14 \% \mathrm{CaHPO}_{4} / \mathrm{CaH}_{2} \mathrm{PO}_{4}^{+}$, spheres (50 min): $\mathrm{Ca}_{2}\left(\mathrm{HPO}_{4}\right)_{3}^{2-}$, ribbons $(100 \mathrm{~min}):$ $\mathrm{Ca}_{6}\left(\mathrm{HPO}_{4}\right)_{4}\left(\mathrm{PO}_{4}\right)_{2}^{2-}$ and plates $(180$ and $240 \mathrm{~min}): \mathrm{Ca}_{8}\left(\mathrm{HPO}_{4}\right)_{2}\left(\mathrm{PO}_{4}\right)_{4}$.

Detailed analysis of the high-resolution cryo-TEM images gave $1.3 \pm 0.3 \mathrm{~nm}$ for the diameter and $0.9 \pm 0.3 \mathrm{~nm}$ for the height of the complexes (Supplementary Fig. S8A-D). These TEM values agree well with the calculated values if we take into account that cryo-TEM shows projection images in which the disc-shaped complex can have different orientations with respect to the electron beam.

The structural formula for the (post-nucleation) spherical aggregates $(\mathrm{Ca} / \mathrm{P}=0.67)$ was determined to be $\left[\mathrm{Ca}_{2}\left(\mathrm{HPO}_{4}\right)_{3}\right]^{2-}$. This implies that the nanometre-sized building blocks of ACP observed in Fig. 1d are formed from pre-nucleation complexes on binding a second calcium ion. High-resolution cryo-TEM revealed that these units have an average diameter of $1.2 \pm 0.2 \mathrm{~nm}$ (Supplementary Fig. S8A).

For the ribbons $(\mathrm{Ca} / \mathrm{P}=1.0)$ a composition of $\left[\mathrm{Ca}_{6}\left(\mathrm{HPO}_{4}\right)_{4}\left(\mathrm{PO}_{4}\right)_{2}\right]^{2-}$ was found, which developed into $\mathrm{Ca}_{8}\left(\mathrm{HPO}_{4}\right)_{2}\left(\mathrm{PO}_{4}\right)_{4}$ for the elongated plates $(\mathrm{Ca} / \mathrm{P}=1.33)$. The latter ratio was confirmed by induction-coupled plasma-optical emission spectroscopy (ICP-OES) measurements (marked in Fig. 2b,c) and is consistent with their identification as OCP by FTIR spectroscopy. As WAXS revealed an OCP-like structure for the ribbons, their formula $\left[\mathrm{Ca}_{6}\left(\mathrm{HPO}_{4}\right)_{4}\left(\mathrm{PO}_{4}\right)_{2}\right]^{2-}(\mathrm{Ca} / \mathrm{P}=1.0)$ points to a Ca-deficient OCP. This implies that the OCP structure precedes the development of the OCP chemistry $(\mathrm{Ca} / \mathrm{P}=1.33)$, which is only fully completed in the stage of the plates. Moreover, Fig. 2a shows that the drop of the $\mathrm{pH}$ occurs after the drop in the free calcium concentration. This suggests that the binding of the calcium ions to the negatively charged Ca-deficient OCP is a first step that takes place, before their incorporation in the OCP lattice and the concomitant release of protons.

Mechanism of aggregation. The high charge calculated for the pre-nucleation complexes seems incompatible with their rapid aggregation into polymeric assemblies. However, previous work showed the aggregation of highly charged solutes to be driven by the gain in entropy associated with the release of hydration water ${ }^{32}$ and also the formation of linear supramolecular polymers of charged monomeric units has been described ${ }^{33}$.

Also the observed small negative zeta potential of $\sim-3.5 \mathrm{mV}$ (Fig. 6) seems to contradict the proposed high charge of the polymeric structures. Still, this value is in complete accordance with values calculated for a $3 \mathrm{D}$ assembly of complexes in which hydrodynamic shielding prevents the detection of charge in the interior of the partially penetrable aggregate with hydrodynamic skin depth $\varepsilon$ (Fig. 6, see also Supplementary Methods, 


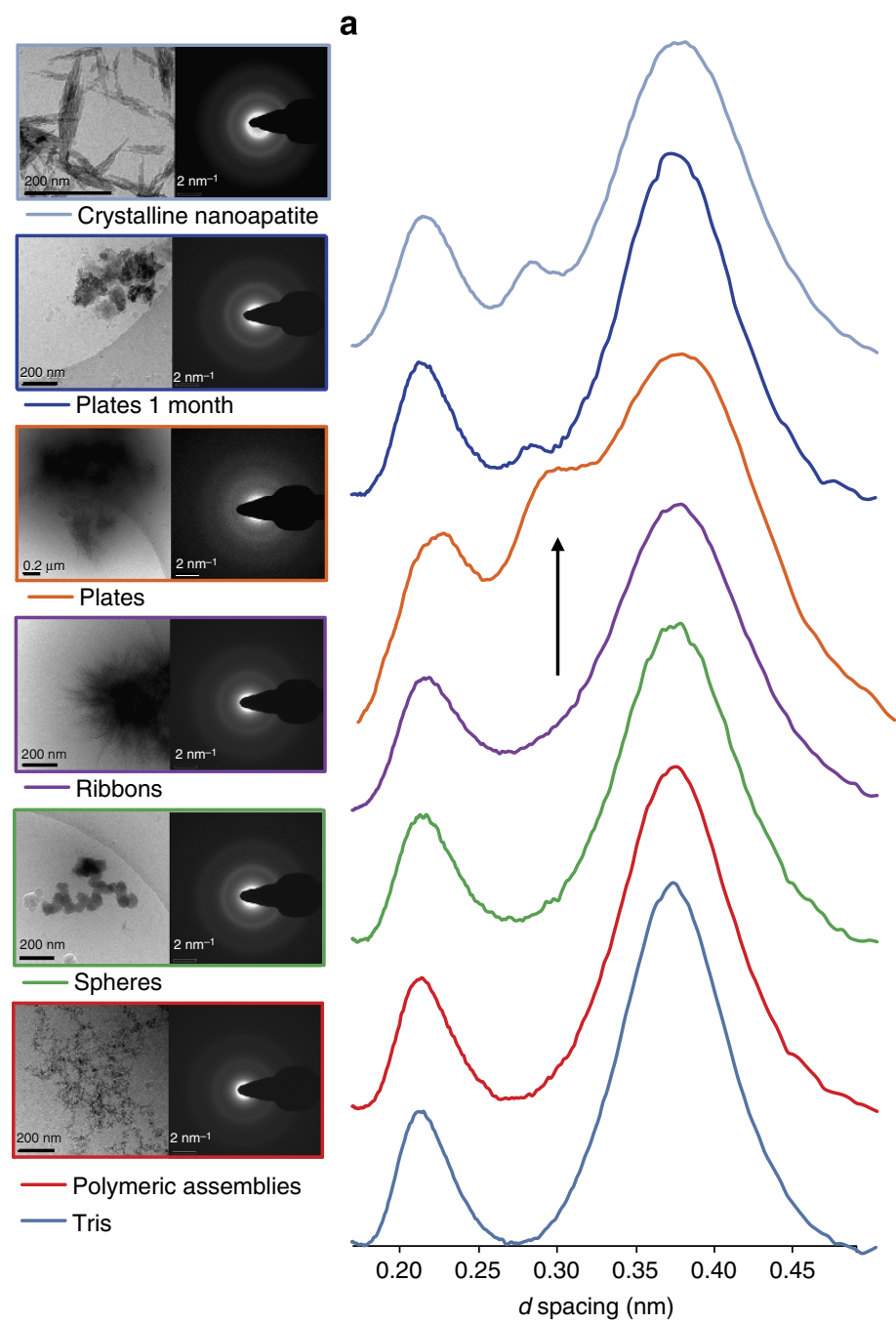

b

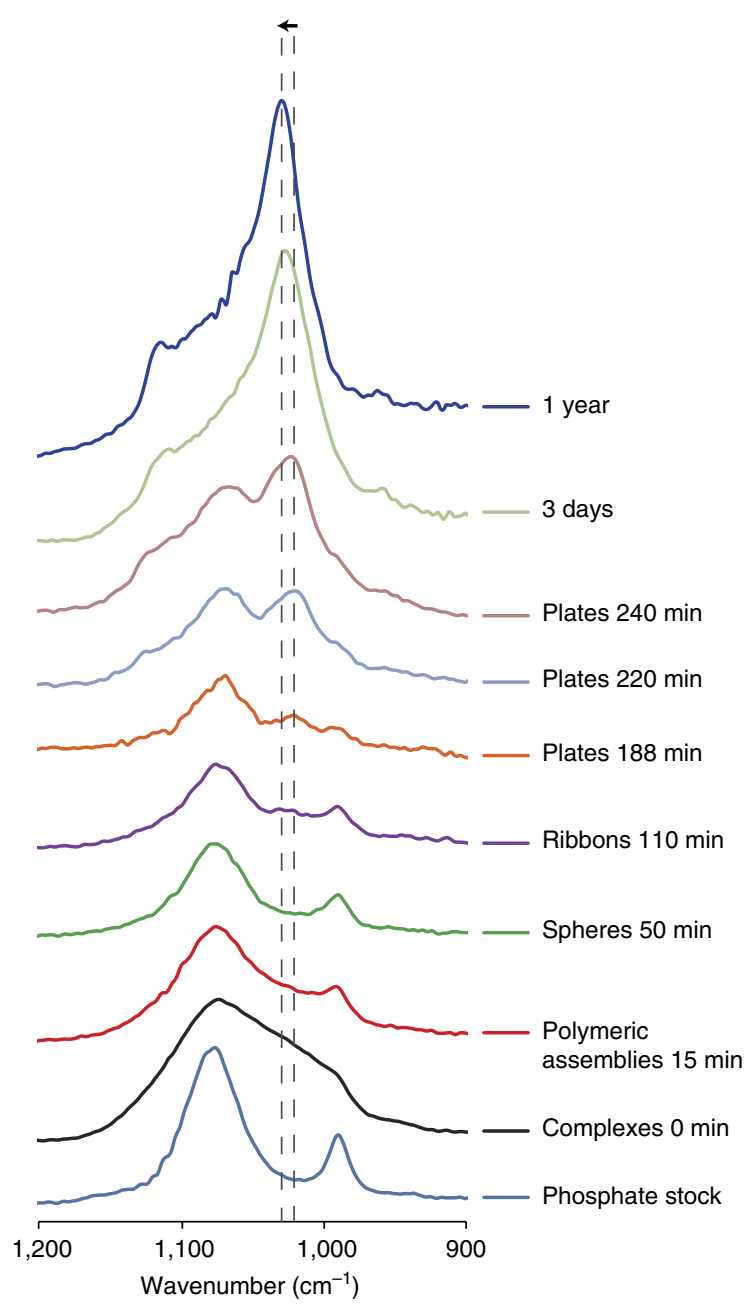

Figure 3 | Electron diffraction and FTIR analysis. (a) Radially averaged electron diffraction data at different stages compared with the tris-buffered saline and crystalline nano-AP, showing the uprising of the OCP signal (arrow) (inset: corresponding raw electron diffraction data and morphology in Cryo-TEM, scale bar, $200 \mathrm{~nm}$ ). (b) In situ FTIR of the calcium phosphate, spectra recorded at different time points in the P-O stretch region. Dotted lines + arrow indicate the shift of the upcoming $\mathrm{PO}_{4}^{3}{ }^{-}$-stretch vibration from 1,021 to $1,030 \mathrm{~cm}^{-1}$. In the first two stages, the signals observed correspond to vibrations of $\mathrm{HPO}_{4}^{2-}$ and $\mathrm{H}_{2} \mathrm{PO}_{4}^{-}$(pre-nucleation) and $\mathrm{HPO}_{4}^{2-}$ (post-nucleation), respectively. The $\mathrm{PO}_{4}^{3-}$-stretch vibration at $1,021 \mathrm{~cm}{ }^{-1}$

characteristic for $\mathrm{OCP}^{51}$ first appears in the stage of the ribbon-like structures and further develops in the stage of the plates, which upon aging shifts to $1,030 \mathrm{~cm}^{-1}$ confirming the conversion into $\mathrm{AP}^{31,52}$

zeta-potential calculations). Upon the formation of the spherical nodules and aggregated spheres (Fig. 6, Structures 2 and 3), the zeta potential diminishes further as they represent (an aggregate of) opaque structures.

The aggregation process was also investigated using dual-axis cryo-electron tomography in combination with 3D box counting (Fig. 5e, Supplementary Fig. S9). This revealed the 3D structure as well as the fractal dimension $\left(D_{\mathrm{f}}=2.2 \pm 0.1\right)$ of the polymeric assemblies, indicating a reaction-limited aggregation (RLCA) process $^{34}$. Based on the structure of the ion-association complexes, it is likely that their aggregation involves hydrogen bonding (see Fig. 5c). This will be most efficient in the conformation that allows double, bidentate hydrogen bond formation between two complexes, as suggested for protonated phosphate groups in solution ${ }^{35}$. This explains the reaction-limited nature of the aggregation process.

Binding of calcium and associated loss of structural water during the transformation into post-nucleation species leads to a further cross-linking of the complexes, and a concomitant densification of their packing (Figs 1c,5e). Indeed, analysis of the aggregates of post-nucleation clusters in ACP revealed a fractal dimension of $2.7 \pm 0.1$ (Supplementary Fig. S9), corresponding to a denser, more ordered packing than for the polymeric assemblies in the pre-nucleation stage. This reorganization of the cluster packing also demonstrates the dynamic nature of the interactions in the $3 \mathrm{D}$ polymeric structures, in line with the proposed hydrogen bond formation between the pre-nucleation complexes.

From the ACP spheres an OCP-like structure evolves, for which the observed thickness $(\approx 1.4 \mathrm{~nm})$ is in accordance with the structural characteristics of OCP-that is, a zig-zag arrangement of rows of calcium triphosphate complexes fused through binding of additional calcium ions (Fig. 5e) ${ }^{27}$.

Thermodynamics of a growth mechanism based on complexes. This study, as well as other recent research, has demonstrated that the formation of AP can occur through the conversion of an 

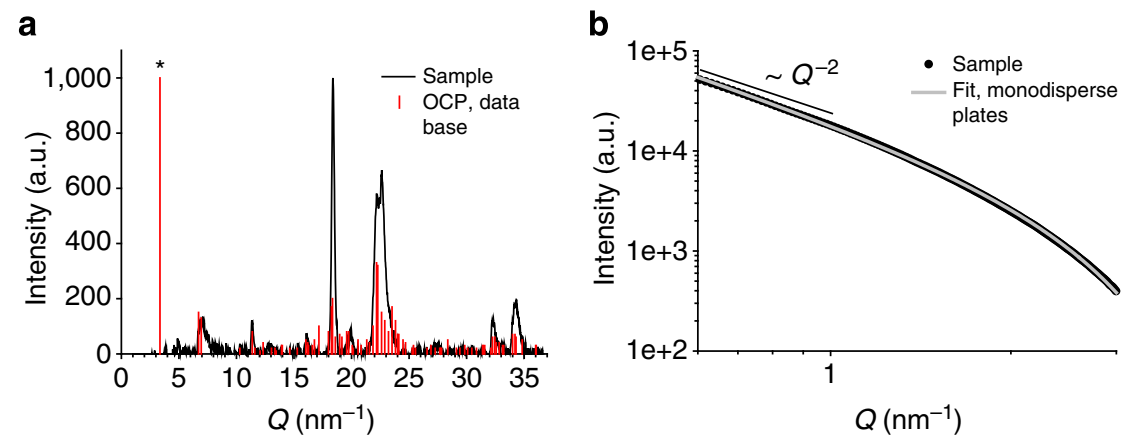

Figure 4 | Synchrotron X-ray scattering analysis. (a) WAXS profile of the ribbons taken after 75 min reaction (black curve) and comparison with the diffraction pattern expected for OCP (red drop lines, pdf2 database entry \#00-026-1056). The asterisk denotes the position of the usually strong peak at $3.36 \mathrm{~nm}^{-1}$ corresponding to the spacing between the $\{100\}$ lattice planes in OCP. This peak is absent in the scattering pattern of the ribbons. The scattering pattern of the ribbons was obtained after solvent subtraction (position shift: $200 \mu \mathrm{m}$ ) and residual background correction performing a polynomial baseline fit (Match! Software, Crystalllmpact, Germany). (b) SAXS pattern of ribbons taken after 75 min reaction (log-log scale). The decay proportional to $Q^{-2}$ at low $Q$ indicates plate-like features ${ }^{53}$. The grey line represents a fit with the scattering function of monodisperse plates of thickness ( $L$ ) plus a constant background (c) using the following equation: $I(Q)^{\star} Q^{2}=a^{\star}\left(\sin \left(Q^{\star} L / 2\right) /\left(Q^{\star} L / 2\right)\right)^{2}+c$, where parameter $a$ depends on the contrast and the experimental setup ${ }^{54}$. This yields the parameters: $a=20,754 \pm 30, L=1.40 \pm 0.01 \mathrm{~nm}, c=194 \pm 1$. In the plot presented here, parameter $c$ was subtracted from the experimental profile as well as from the fitting curve.

amorphous precursor phase $\mathrm{e}^{36}$ that forms via a cluster-growth mechanism $^{14,15}$. We now must assume that it also involves the aggregation of pre-nucleation complexes. To investigate the consequences of this nucleation-complex-based mechanism on the energy barriers associated with AP formation, we used in situ AFM, which allows one to directly monitor mineralization processes on surfaces with sub-nanometre detail ${ }^{37}$.

To avoid competitive nucleation in the bulk solution, the substrates used for these AFM experiments were coated with collagen. Owing to its widespread role as an organic matrix for calcium phosphate nucleation in biological dentine and bone, we reasoned collagen would provide a low interfacial energy and thus high nucleation rates at low supersaturation. Using these collagen substrates, we found it possible to measure the nucleation rates of calcium phosphate within minutes to hours, depending on the supersaturation, $\sigma$ (see Methods for details on solubility and calculating supersaturations), with no concomitant nucleation in the solution. At values of $\sigma_{\mathrm{AP}} \leq 3.08\left(\sigma_{\mathrm{ACP}} \leq-0.23\right)$, the smallest features detected were composed of AP (Fig. $7 \mathrm{a}-\mathrm{c})$. Note that the solution is undersaturated with respect to ACP; thus any ACP that forms is owing to inherently unstable and transient fluctuations, which we would not see by AFM. However, for values of $\sigma_{\mathrm{AP}} \geq 3.36\left(\sigma_{\mathrm{ACP}} \geq 0.04\right)$, the first phase to form was ACP, which transformed first to OCP and then to AP (Fig. 7d-f), consistent with the cryo-TEM results (see also Supplementary Fig. $\mathrm{S} 10)$. In both cases, the first particles to form were $1-2 \mathrm{~nm}$ in size and grew with time. Moreover, the morphologies observed by AFM and subsequent $e x$ situ TEM (Fig. 7d-f, insets) at $\sigma_{\mathrm{AP}} \geq 3.36$ were similar to those seen by cryo-TEM; nm-size particles forming spheroidal aggregates that transform first into spherulites of OCP and, finally, into plate-like crystals of AP.

To analyse these data, as a starting point we assume that nucleation occurs through ion-by-ion growth in accordance with classical nucleation theory. Then the interfacial energy $\alpha$ of the nucleating phase can be determined from the number density of nucleation events versus time using the classical expressions (Fig. $7 g)^{1,2}$.

Applying this analysis to heterogeneous nucleation of hemispherical particles, we obtain values of 40 and $90 \mathrm{~mJ} \mathrm{~m}^{-2}$ for $\alpha_{\mathrm{ACP}}$ and $\alpha_{\mathrm{AP}}$, respectively (see Supplementary Methods for details). Based on solubilities, the values of $\alpha_{\mathrm{ACP}}$ and $\alpha_{\mathrm{AP}}$ in bulk solution are expected to be about 150 and $180 \mathrm{~mJ} \mathrm{~m}^{-2}$, respectively ${ }^{38}$. Consequently, the experimental values of $\alpha$ appear reasonable for nucleation on a substrate that promotes nucleation. However, the magnitudes of the thermodynamic barriers to nucleation implied by these values demonstrate a dramatic failure of the classical expressions for ion-by-ion nucleation. In these expressions, $\Delta G_{c}$ (see caption of Fig. 7) scales with $\alpha^{3} / \sigma^{2}$. Taking the values of $\sigma$ for AP and ACP at the conditions where the first phase to appear changes from the former to the latter $\left(\sigma_{\mathrm{AP}}=3.36, \sigma_{\mathrm{ACP}}=0.04\right)$, we find that $\Delta \mathrm{G}_{\mathrm{C}}$ for ACP formation should be about 600 times that for AP formation. In addition, as shown by Fig. $8 \mathrm{a}$, which is a plot of $\Delta G$ versus $R$ using the value of $\alpha_{\mathrm{ACP}}$ determined from the data in Fig. $7 \mathrm{~g}$, in this scenario the value of the barrier to ACP nucleation is more than three orders of magnitude greater than $\mathrm{kT}$. Moreover, the critical radius $R_{\mathrm{c}}$, given by the particle radius at which the free-energy change in Fig. 8a reaches a maximum, should be $\sim 10 \mathrm{~nm}$, which is much larger than the 1-2 nm sizes of the first features observed experimentally. Similarly, for the homogeneous nucleation of ACP under the conditions used in the cryo-TEM experiments $\left(\sigma_{\mathrm{AP}}=3.8\right.$ and $\left.\sigma_{\mathrm{ACP}}=0.69\right)$ and using the interfacial energies in bulk solution, we calculate that $\Delta G_{\mathrm{c}}$ is expected to be yet three times larger than for nucleation on collagen, and 18 times that of AP in the same solution. To put these barriers in perspective, even if the pre-factor A was equivalent to the attempt frequency for atomic vibrations at room temperature $\left(6 \times 10^{12} \mathrm{~Hz}\right)$, the barrier would have to be of order $30 \mathrm{kT}$ or less to get significant rates of nucleation. Consequently, ACP should never form under these conditions.

This analysis does not take into account any size dependence in the effective interfacial energy. In reality, below some size limit $R_{\infty}$ in the nm range this energy must diminish, reaching zero at the length scale of ion pairs. This size dependence can have significant consequences for both the stability of phases ${ }^{3}$ and the barriers to nucleation ${ }^{39}$. However, the effect only becomes a factor of importance when $R_{\mathrm{c}}$ is comparable to $R_{\infty}$, whereas the $7 \mathrm{~nm}$ critical radius for ACP formation predicted by classical theory is well above that at which size dependence should be a factor. Even if we set the interfacial energy to zero at the dimension of an ion pair $(\sim 4 \AA)$ and assume it reaches its bulk value only at a particle diameter greater than $5 \mathrm{~nm}$, which is about two times the typical dimension considered appropriate ${ }^{39}$, the barrier remains insurmountable. As shown in Fig. 8b, which is a 
a

$\mathrm{Ca}_{\mathrm{x}}\left(\mathrm{HPO}_{4}\right)_{\mathrm{y}}\left(\mathrm{H}_{2} \mathrm{PO}_{4}\right)_{z}^{2 \mathrm{x}-2 \mathrm{y}-\mathrm{z}} \stackrel{\mathrm{K}_{\mathrm{Eq}}}{\rightleftarrows} \mathrm{x} \cdot \mathrm{Ca}^{2+}+\mathrm{y} \cdot \mathrm{HPO}_{4}^{2-}+\mathrm{z} \cdot \mathrm{H}_{2} \mathrm{PO}_{4}^{-}$
C

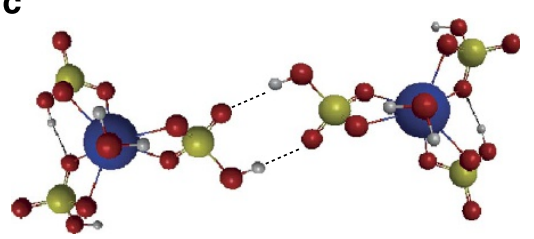

d

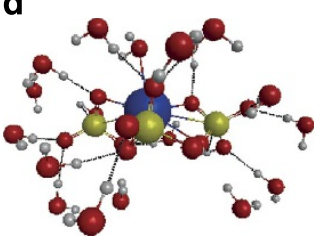

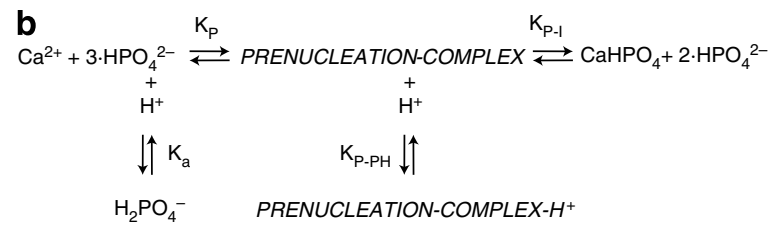

e
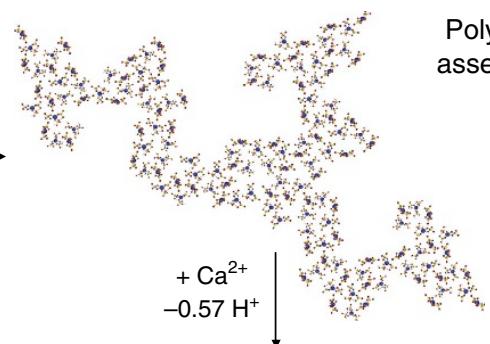

Polymeric assemblies

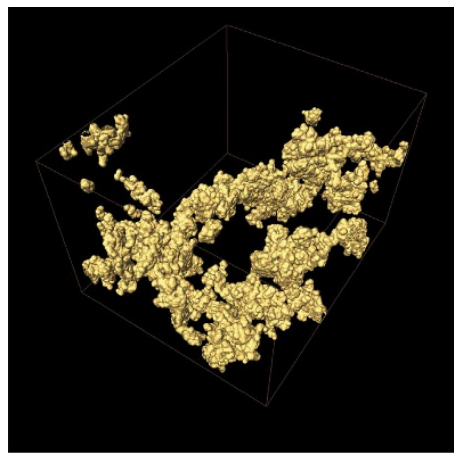

Ribbons

(Ca-deficient OCP)

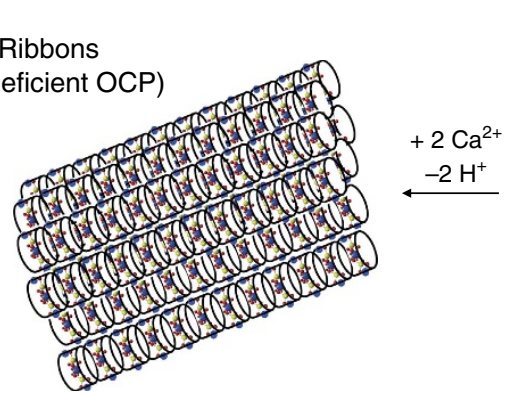

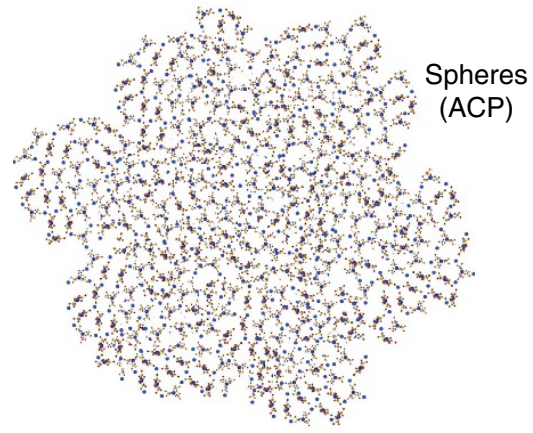

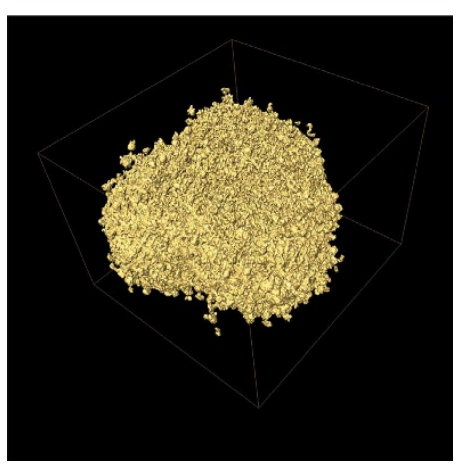

Figure 5 | Chemical and structural modelling. (a) Overall equilibrium in pre-nucleation stage. (b) Equilibria between pre-nucleation complexes, ion pairs and ions in the pre-nulceation stage. $K_{\mathrm{eq}} K_{\mathrm{a}} K_{\mathrm{p}}, K_{\mathrm{p}-\mathrm{PH}}$ and $K_{\mathrm{p}-1}$ are the corresponding equilibrium constants. (c,d) Structure of the pre-nucleation complex derived from $a b$ initio calculations. (c) Dimer of the complex showing the potential of hydrogen bond formation, (d) complex with hydration shell. The $a b$ initio geometry optimizations were performed at the Hartree-Fock level with a 6-31 $G^{\star \star}(\mathrm{dp})$ basis set using the GAMESS software. The solvent (water) was described both explicitly, by surrounding the complex with 18 water molecules to account for the first hydration shell, and implicitly, using the conductor-like polarizable continuous model to describe the bulk solvent around the explicitly solvated complex. These calculations further indicated that the complexes have a hydration sphere with an outer diameter of $1.5 \mathrm{~nm}$, consisting of 15 water molecules forming $\mathrm{H}$ bonds with the phosphate oxygen atoms. (e) Mechanism of aggregation. Pre-nucleation complexes in solution forming branched polymeric assemblies by a reactionlimited aggregation (RLCA) process. Nucleation of ACP occurs through the binding of additional calcium ions and the subsequent aggregation of the resulting post-nucleation cluster. This post-nucleation cluster also is the basis of the crystal structure of octacalcium phosphate (and of AP), which forms through the further uptake of calcium ions. 3D computer visualizations of cryo-electron tomograms of the polymeric assemblies and spheres are given next to their schematic representations.

plot of $\Delta G$ versus $R$ using the same parameters as in Fig. 8a with the addition of a size dependent $\alpha$, for a reasonable range of $R_{\infty}$ little or no change in $\Delta G_{\mathrm{c}}$ or $R_{\mathrm{c}}$ is predicted in the range of supersaturations relevant to the AFM experiments. For example, when $\sigma_{\mathrm{ACP}}=0.15$ for $R_{\infty}$ ranging from $1-3 \mathrm{~nm}$, the barrier is still over $500 \mathrm{kT}$. For homogeneous nucleation at the supersaturation used in the TEM experiments, owing to the much larger value of $\alpha_{\infty}\left(100\right.$ versus $\left.40 \mathrm{~mJ} \mathrm{~m}^{-2}\right)$, the barrier is much larger still.

The failure of the classical picture can be understood when the presence of the pre-nucleation complexes and the complex pathway to the crystalline state observed by cryo-TEM are taken into account. The origin of the barrier in the classical nucleation equation is the introduction of an excess free energy-over that of the bulk solid-that is associated with creation of new surface. However, the pre-nucleation complexes themselves-though they are solution species-have a certain excess free energy over that of the free ions that is associated with their surface. (In this regard, they differ from the pre-nucleation clusters postulated in the calcium carbonate system, which are said to be lower in free energy than the free ions.) Evidence for this surface energy can be found in the fractality of the polymeric assemblies, whose packing of complexes in the reaction limited (RLCA) range differs substantially from the open diffusion limited (DLCA) geometry described for structures at the zero surface tension limit ${ }^{40}$. When the complexes combine to form a larger particle, the elimination of this excess free energy $\Delta G_{\mathrm{Ex}}$ must be taken into account and this can have a dramatic effect on the size of the free-energy barrier, as well as the critical radius. To evaluate the effect, we can express the change in free energy as a function of particle radius $R$ using:

$$
\Delta G=-\frac{4 \pi f R^{3}}{3 \omega} k T \sigma+4 \pi f R^{2} \alpha(R)-N \Delta G_{\mathrm{Ex}}
$$

where $N$ is the number of complexes that combine to form the particle and $f$ is a geometric factor that depends on nucleus shape, 


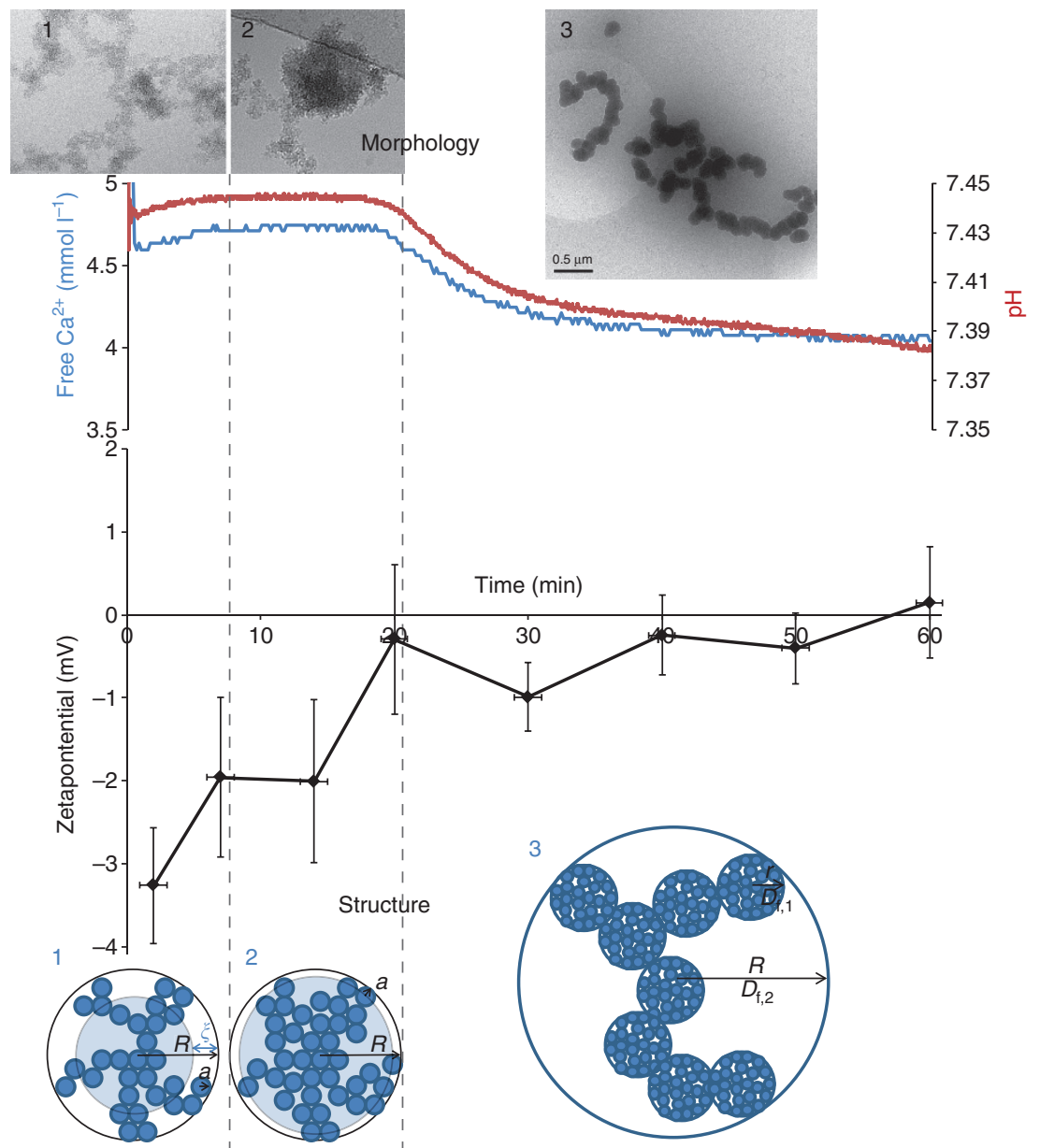

Figure 6 | Zeta potential as function of time $(\boldsymbol{n}=\mathbf{9})$ with corresponding $\mathbf{p H} / \mathbf{C a}^{\mathbf{2}+}$ curve. Morphologies $(1=$ polymeric assemblies, $2=$ spherical nodules and $3=$ aggregated spheres) and structures ( $1=$ partially penetrable, $2=$ opaque spheres, $3=$ aggregate of opaque spheres), $R, a$ and $r$ are radii, $\xi=$ hydrodynamic skin dept, and $D_{\mathrm{f}, 1}, D_{\mathrm{f}, 2}$ are fractal dimensions. Zeta potentials were measured in transmission at a $50 \mathrm{~V}$ effective voltage (average over 100 runs). The Von Smoluchowski equation ${ }^{55}$ was applied, considering the high ionic strength used $(I=0.2 \mathrm{M})$ and size of the polymeric aggregates $(>100 \mathrm{~nm})$. Importantly, for the described complexes the distances between the charged moieties inside the complex are not small with respect to the complex size and therefore their interactions deviate from the DLVO theory derived for larger colloidal particles ${ }^{56}$. Hence, the ion-association complexes should not be regarded as particles with a central (negative) charge but as species with localized negative and positive charges that can interact with the opposite charges in neighbouring complexes, favouring their aggregation ${ }^{57,58}$. The presence of high concentrations of $\mathrm{Na}^{+}$counter ions will lead to a significantly reduced effective charge ${ }^{59}$ further facilitating the interaction between the charged complexes ${ }^{60}$.

equalling 1 and $1 / 2$ for spherical and hemispherical nuclei, respectively. This explicitly shows that there is a reduction in $\Delta G$ owing to any excess free energy of the complexes over that of the free ions. For the case of ACP nucleation on collagen, the number of disk-shaped complexes of radius $r$ (with height $=$ radius) that must combine to form an ACP nucleus is given by $N=(4 \pi / 3)$ $(R / r)^{3}$. Attributing $\Delta G_{\text {Ex }}$ exclusively to the complex surface freeenergy $\alpha_{\text {comp }}$ implies that $\Delta G_{\mathrm{Ex}}=4 \pi R^{2} \alpha_{\text {comp. }}$. This leads to a nucleation barrier of:

$$
\Delta G_{\mathrm{C}}=\frac{16 f \pi \omega^{2} \alpha^{3}}{3(k T \sigma)^{2}}\left(1+\frac{4 \omega \alpha}{r k T \sigma} \eta\right)^{-2}, \eta=\frac{\alpha_{\mathrm{comp}}}{\alpha}
$$

Comparison of equation 2 with the classical expression shows that $\Delta G_{\mathrm{c}}$ is now given by the product of the free-energy barrier for nucleation directly from molecular species and a correction term that is always $\leq 1$ and whose value scales with the ratio of the complex surface energy to that of the newly nucleated phase. Moreover, because the surface energy terms dominate at low $\sigma$, the impact on $\Delta G_{c}$ is enormous, even when the surface energy of the complexes is significantly less than that of the nucleating particles. A best fit of equation 2 to the data in Fig. 7 for a value of $\alpha_{\infty}$ in the range of $100-150 \mathrm{~mJ} \mathrm{~m}^{-2}$ gives a value of about $1 / 15$ for $\eta$. For ratios of the complex-to-bulk surface energy $(\eta)$ of this size or larger, Fig. $8 \mathrm{c}$ shows that both $\Delta G_{\mathrm{c}}$ and $R_{\mathrm{c}}$ are dramatically reduced. In fact, for sufficiently large values, the barrier can be completely eliminated so that nucleation proceeds downhill in free energy. For example, when $\sigma_{\mathrm{ACP}}=0.15$, the barrier disappears for all values of $\alpha_{\text {comp }}$ greater than $10 \%$ of $\alpha_{\infty}$, or conversely, when $\alpha_{\text {comp }}$ is greater than $10 \%$ of $\alpha_{\infty}$, it is eliminated for all $\sigma_{\mathrm{ACP}} \geq 0.15$. Figure $8 \mathrm{c}$ also shows that, for the slightly greater value of $\sigma_{\mathrm{ACP}}=0.4$, there is no barrier for $\alpha_{\text {comp }}$ greater than only $6.7 \%$ of $\alpha_{\infty}$. Thus the aggregation of the prenucleation complexes followed by binding of $\mathrm{Ca}^{2+}$ may avoid the insurmountable thermodynamic barrier faced during ion-byion nucleation of ACP predicted in Fig. 8a,b. As a result, the pathway to the final crystalline state should be controlled by kinetic barriers associated with the chemical reactions and structural rearrangements revealed by cryo-TEM. As this analysis describes the heterogenous nucleation of ACP on a 

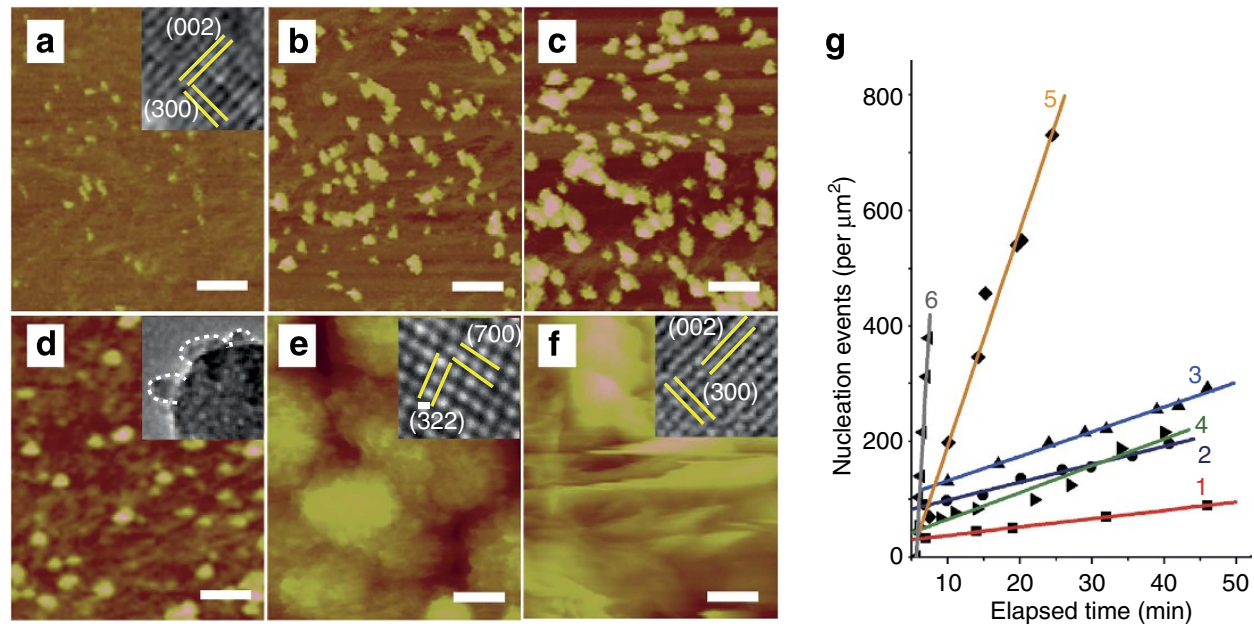

Figure 7 | Results of in situ AFM investigation of ACP and AP nucleation kinetics. (a-c) Nucleation of HAP on collagen at (a) $t=270,(\mathbf{b}) 1,020$ and (c) $5,280 \mathrm{~s}$, respectively, where $\sigma_{\mathrm{AP}}=3.08, \sigma_{\mathrm{OCP}}=1.51$ and $\sigma_{\mathrm{ACP}}=-0.23$. (d) Nucleation of ACP on collagen followed by transformation to (e) OCP and then (f) AP at (d) $t=552$, (e) 3,660 and (f) 6,000 s, respectively, where $\sigma_{\mathrm{AP}}=3.36, \sigma_{\mathrm{OCP}}=1.76$ and $\sigma_{\mathrm{ACP}}=0.04$. Inserts are TEM images of mineral phase (a) AP, (d) ACP (e) OCP and (f) AP. Scale bars in AFM images are $100 \mathrm{~nm}$. (g) Dependence of the steady-state nucleation rate $J_{\mathrm{n}}$ on time $t$ at six different supersaturations. The supersaturations corresponding to the numeric labels are, $1: \sigma_{\mathrm{AP}}=3.08, \sigma_{\mathrm{OCP}}=1.51, \sigma_{\mathrm{ACP}}=-0.23 ; 2$ : $\sigma_{\mathrm{AP}}=3.24, \sigma_{\mathrm{OCP}}=1.65, \sigma_{\mathrm{ACP}}=-0.08 ; 3: \sigma_{\mathrm{AP}}=3.31, \sigma_{\mathrm{OCP}}=1.71, \sigma_{\mathrm{ACP}}=-0.02 ; 4: \sigma_{\mathrm{AP}}=3.45, \sigma_{\mathrm{OCP}}=1.83, \sigma_{\mathrm{ACP}}=0.128 ; 5: \sigma_{\mathrm{AP}}=3.46, \sigma_{\mathrm{OCP}}=1.84$, $\sigma_{\mathrm{ACP}}=0.129$ and 6: $\sigma_{\mathrm{AP}}=3.47, \sigma_{\mathrm{OCP}}=1.85, \sigma_{\mathrm{ACP}}=0.1295$. Analysis of the data using classical nucleation theory, which predicts that $J_{\mathrm{n}}=\mathrm{A} \cdot \exp \left(-\Delta \mathrm{G}_{\mathrm{C}} /\right.$ $\mathrm{kT})=A \cdot \exp \left(-8 \pi \omega^{2} \alpha^{3} / 3(\mathrm{kT} \sigma)^{2}\right)$ where $A$ is the kinetic constant related to diffusional, steric and any other kinetic barriers, $\Delta G_{\mathrm{c}}$ is the free-energy barrier to nucleation, $\omega$ is the molecular volume of the solid, $\alpha$ is the interfacial energy, $k$ is Boltzmann's constant and $T$ is the absolute temperature, gives $\alpha_{\mathrm{ACP}}=40 \mathrm{~mJ} \mathrm{~m}^{-2}$ and $\alpha_{\mathrm{AP}}=90 \mathrm{~mJ} \mathrm{~m}^{-2}$ (see Supplementary Information Analysis of nucleation data: fitting of classical nucleation rate equation for details.) We note that nucleation on a substrate is completely equivalent to nucleation in the bulk solution in terms of this equation, which does not distinguish between heterogeneous and homogeneous nucleation except through the differences in $\alpha$ and the numerical factor $8 / 3$.

a

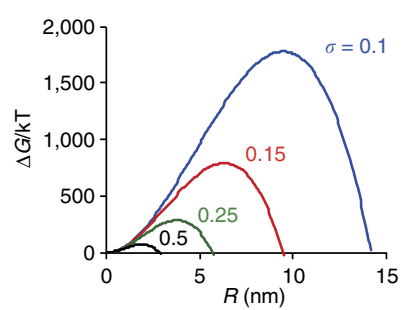

b

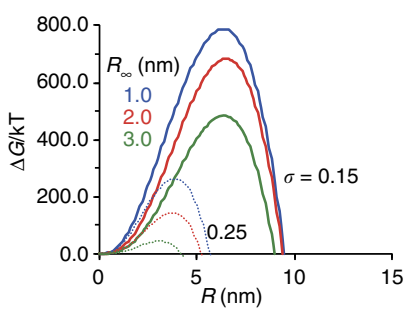

C

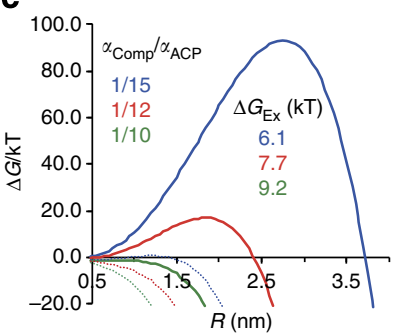

Figure 8 | Effect of supersaturation, size dependent surface energy, and cluster excess free energy on classical nucleation barrier. (a) Dependence of free-energy change $\Delta G$ on radius of nucleus $R$ based on the classical expression for heterogeneous ion-by-ion nucleation $\Delta G=-\left(2 \pi R^{3} / 3 \omega\right) \cdot k T \sigma+2 \pi R^{2} \alpha$ of hemispherical ACP for $\alpha_{A C P}=40 \mathrm{~mJ} \mathrm{~m}{ }^{-2}$ (derived from Fig. 7), values of $\sigma$ as specified next to the curves, and other symbols as defined in Fig. 7. (See Supplementary Information Analysis of nucleation data: fitting of classical nucleation rate equation for details.) (b) Impact of size-dependent interfacial free energy on the barrier for heterogeneous ion-by-ion nucleation of hemispherical ACP, as based on equation 1. Many forms for this dependence have been proposed; however, the exact dependence chosen has only a minor effect on the predicted change in nucleation rates. Here, we assume an exponential dependence, $\alpha_{\mathrm{ACP}}(R)=\alpha_{\infty}\left[1-\exp \left(-\left(R-R_{0}\right) / R_{\infty}\right)\right]$, where $\alpha_{\infty}$ is the surface energy for the bulk phase, $R_{0}$ is on the order of the molecular radius of the nucleating species and $R_{\infty}$ is the characteristic particle radius at which the interfacial energy approaches the bulk value. Typical literature values for $R_{0}$ are $\sim 2 \AA$, which we use here ${ }^{39}$. Curves are shown for $R_{\infty}=1 \mathrm{~nm}$ (blue lines), $2 \mathrm{~nm}$ (red lines) and $3 \mathrm{~nm}$ (green lines), assuming $\sigma_{\mathrm{ACP}}=0.15$ (solid lines) or 0.25 (dashed lines) and $\alpha_{\infty}=40 \mathrm{~mJ} \mathrm{~m}^{-2}$. All other parameters are as in Fig. 8a. Comparison of the solid curves of (b) with the red curve in (a) shows that the size dependence of surface energy shifts the free-energy barrier to slightly lower values and decreases $R_{\mathrm{c}}$ by a minor amount. (c) Dependence of free energy on nucleus size and ratio of complex to ACP surface energy $\left(\alpha_{\text {comp }} / \alpha_{A C P}\right)$ according to equations 1 and 2 during heterogeneous nucleation of hemispherical ACP through aggregation of $1.1 \mathrm{~nm}$ disk-shaped complexes for $\alpha_{\mathrm{ACP}}(R)=\alpha_{\infty}\left[1-\exp \left(-\left(R-R_{0}\right) / R_{\infty}\right)\right] \mathrm{with}_{\infty}=100 \mathrm{~mJ} \mathrm{~m}^{-2}, R_{0}=2 \AA$ and $R_{\infty}=1 \mathrm{~nm}$, where values of $\alpha_{\text {comp }} / \alpha_{\mathrm{ACP}}$ and the corresponding $\Delta G_{\mathrm{Ex}}$ are specified in the legend. Note that here $\alpha_{\infty}$ refers to the interfacial free energy of bulk $\mathrm{ACP}$ in solution, which we have conservatively taken as $100 \mathrm{~mJ} \mathrm{~m}^{-2}$. Heavy solid curves: $\sigma_{\mathrm{ACP}}=0.15$, light solid curves: $\sigma_{\mathrm{ACP}}=0.4$.

collagen substrate, an extension for homogenous nucleation, as observed in cryo-TEM, was derived and is given in the Supplementary Note 1.

Nothing in the above analysis requires the nucleating phase to be ACP. Thus, the impact of the pre-nucleation complexes on the free-energy barrier to AP formation should also be manifest.
However, to go directly from these complexes to the ordered crystal requires both more extensive chemical transformations than needed for ACP formation, as well as structural transformations that are not a factor in ACP nucleation. Hence, the kinetic barriers to AP formation are likely to exceed those for ACP formation and, once the ACP phase boundary is crossed, 
ACP quickly becomes the dominant phase to emerge from the supersaturated solution.

\section{Discussion}

In 1974, Betts and Posner ${ }^{41}$ demonstrated that ACP consisted of subunits already containing some of the structural features of AP and proposed these subunits-later termed Posner's clusters-to be $\mathrm{Ca}_{9}\left(\mathrm{PO}_{4}\right)_{6}$. They assigned peaks in the radial distribution functions derived from $\mathrm{X}$-ray data to the atom pairs $\mathrm{P}-\mathrm{O}(1.5 \AA)$, $\mathrm{O}-\mathrm{O}$ and $\mathrm{Ca}-\mathrm{O}(2.3 \AA)$, and $\mathrm{Ca}-\mathrm{Ca}, \mathrm{Ca}-\mathrm{P}$ and P-P (3-6 $\mathrm{A}$ ). These values agree well with the distances derived from the $a b$ initio calculations for the pre-nucleation complexes, which are $\mathrm{P}-\mathrm{O}(1.6 \pm 0.1 \AA), \mathrm{Ca}-\mathrm{O}(2.5 \pm 0.1 \AA), \mathrm{Ca}-\mathrm{P}(3.0 \pm 0.1 \AA)$ and P-P $(5.1 \pm 0.3 \AA$ ) (see also Supplementary Table S3). Actually, the Posner's cluster can be seen as two deprotonated pre-nucleation complexes in which all negative charges are compensated by complexing calcium ions. And although the Posner's cluster became regarded as a spherical particle with a diameter of $9.5 \AA$, in the original paper the cluster was proposed to 'be large enough to contain atom pairs with about $9.5 \AA$ spacing'. Moreover, a small but significant peak at $12.1 \AA$ was attributed to interparticle distances', but perfectly describes the close packing of the present $1.2 \mathrm{~nm}$ post-nucleation clusters in ACP.

The $\mathrm{Ca} / \mathrm{P}$ ratios of $\mathrm{ACP}$ reported in the literature vary between 1.1 and 1.6 (ref. 36), hence distinctly differ from the value of 0.67 calculated from our $\mathrm{pH}$ and Ca-ISE measurements. However, as it was demonstrated recently that drying of ACP can strongly affect the structure of the resulting material ${ }^{42}$, the ACP in solution was isolated by filtration, washing and drying (Supplementary Methods, analysis of calcium phosphate precipitate). For this material, energy dispersive $\mathrm{X}$-ray analysis revealed a $\mathrm{Ca} / \mathrm{P}$ ratio of 1.5 (Supplementary Table S4), demonstrating that our isolated ACP does not deviate from the isolated materials described in the literature. However, the different $\mathrm{Ca} / \mathrm{P}$ ratios found for the $\mathrm{ACP}$ in solution and the isolated ACP underline the fact that concentration and isolation of hydrated ACP leads to phase changes in the material.

The presence of $\mathrm{HPO}_{4}^{2-}$ in $\mathrm{ACP}$ - as implied by the postnucleation cluster chemistry- is different from the structure of $\mathrm{Ca}_{9}\left(\mathrm{PO}_{4}\right)_{6}$ commonly considered for ACP. However, infrared and solid-state NMR studies have demonstrated the presence of $\mathrm{HPO}_{4}^{2-}$ in synthetic $\mathrm{ACP}^{36}$ while others indicated its presence in the non-apatitic components of bone $e^{43}$.

By combining cryo-TEM with several in situ analysis techniques and $a b$ initio calculations, we conclude that the previously reported nanometre entities termed pre-nucleation clusters for calcium phosphate ${ }^{14}$ are in fact soluble ionassociation complexes $\left[\mathrm{Ca}\left(\mathrm{HPO}_{4}\right)_{3}\right]^{4-}$ that form aggregates in solution. Above the solubility limit of ACP, these aggregated prenucleation complexes take up calcium ions from solution to form insoluble post-nucleation clusters of $\left[\mathrm{Ca}_{2}\left(\mathrm{HPO}_{4}\right)_{3}\right]^{2-}$ that precipitate as ACP. Our results show, in contradiction to the previously postulated cluster-growth mechanism ${ }^{16}$, that the clusters do not actually represent a fixed structural unit, but that the chemistry of these building blocks progresses stepwise towards the composition of the final product, AP. However, the calcium triphosphate structure of the initial complexes is retained throughout these steps. The fact that the previously identified pre-nucleation clusters are merely ion-association complexes of one calcium and three phosphate ions places them in the realm of inorganic solution chemistry. Nonetheless, the existence of these pre-nucleation complexes, which have an excess free energy, fundamentally alters the nucleation pathway by making amorphous phases accessible at concentrations for which classical nucleation theory would predict the exclusive formation of the more stable crystalline phases. Nevertheless, the extended nucleation theory we present here is well capable of explaining these results. The observed formation of polymeric assemblies bears strong resemblance to the formation of, for example, the liquid-like clusters proposed for lysozyme ${ }^{19}$, of mass fractals as proposed for glycine ${ }^{20}$ and the liquid-like ionic polymers suggested for calcium carbonate ${ }^{44}$. This strongly suggests that the polymerization of basic building blocks that we describe here as the first step in crystal formation is not unique for the crystallization of calcium phosphate, but is a far more general phenomenon in both organic and inorganic systems. It is likely that also these 'non-classical' nucleation mechanisms can be explained by the extended nucleation theory presented here.

\section{Methods}

Mineralization reaction. The mineralization reaction is performed in a Trisbuffered saline, consisting of $50 \mathrm{mM}$ Trizma base (Sigma-Aldrich, USA) and $150 \mathrm{mM} \mathrm{NaCl}$ (Merck, Germany) in ultrapure water (Millipore, USA) set at $\mathrm{pH}=7.40$ using $\mathrm{HCl}$ (25\%, Merck). A $10 \mathrm{mM}$ calcium stock and a $10 \mathrm{mM}$ phosphate stock were prepared by dissolving $\mathrm{CaCl}_{2}{ }^{\star} 2 \mathrm{H}_{2} \mathrm{O}$ (Sigma) and $\mathrm{K}_{2} \mathrm{HPO}_{4}$ (Merck) in Tris-buffered saline, after which the $\mathrm{pH}$ was adjusted to 7.40 using $0.1 \mathrm{M} \mathrm{NaOH}$ (Merck) or $0.1 \mathrm{M} \mathrm{HCl}$. The reaction was performed at $19 \pm 1^{\circ} \mathrm{C}$ in a $50 \mathrm{ml}$ beaker or $10 \mathrm{ml}$ sample vial, to which 14.7 or $3.53 \mathrm{ml}$ calcium stock was added. The calcium stock was stirred gently at 200 r.p.m. before adding 10.3 or $2.47 \mathrm{ml}$ phosphate stock $(\mathrm{Ca} / \mathrm{P}=1.43)$. The reaction was followed under stirring for typically $1-4 \mathrm{~h}$. According to Termine et al. ${ }^{45}$, conditions were chosen to achieve initial phase separation of ACP within 15-20 min.

Cryogenic Transmission Electron Microscopy. Samples $(3 \mu \mathrm{l})$ were vitrified at different time points using an automated vitrification robot (FEIVitrobot ${ }^{\mathrm{TM}}$ Mark $^{\mathrm{N}}$ III, FEI Company). R2/2 Quantifoil Jena grids (Quantifoil Micro Tools GmbH, Germany) were surface plasma treated before the vitrification procedure using a Cressington 208 carboncoater. The cryo-TEM experiments were performed on a FEI Tecnai 20 (type Sphera, $\mathrm{LaB}_{6}, 200 \mathrm{kV}, 1 \mathrm{k} \times 1 \mathrm{k}$ Gatan CCD camera) TEM on the TU/e CryoTitan (FEI) (FEG, $300 \mathrm{kV}$, Gatan Energy Filter, $2 \mathrm{k} \times 2 \mathrm{k}$ Gatan CCD camera, www.cryotem.nl) or on the Nanoport Eindhoven Titan Krios (FEI) (FEG, $300 \mathrm{kV}$, Falcon direct electron detector). A cryo-holder (Gatan Inc., USA) operating at $\sim-170^{\circ} \mathrm{C}$ was used with the Tecnai 20 .

LDSAED was performed on the FEI Technai 20 (type Sphera) TEM (camera length $520 \mathrm{~mm}$, selected area $0.29 \mu \mathrm{m}$ ). Radial averaging of the diffraction pattern using DiffTools ${ }^{46}$ in Digitial MicrographTM software (version 3.10.0, Gatan) and the Radial Profile Angle plug-in in ImageJTM software (version 1.42q, NIH, USA). A $1 / \mathrm{q}$ background correction was performed to diminish the contribution of the zero-loss beam. As a standard for crystalline AP, nanocrystalline HAP suspension in ethanol (Berkeley Advanced Biomaterials Inc., USA) was diluted using $0.01 \mathrm{M}$ acetic acid to a concentration of $600 \mathrm{mg} \mathrm{ml}^{-1}$.

Dual-axis cryo-Electron tomography was performed on the TU/e CryoTitan (FEI). Two orthogonal tilt series were recorded between negative tilt angles of $-70^{\circ}$ to $-65^{\circ}$ and positive tilt angles $60^{\circ}-70^{\circ}$ (magnification $\times 30,000$, defocus $-3.50 \mu \mathrm{m}$, total dose $45-54$ electrons $\AA^{-2}$ ). The tilt step was $2^{\circ}$ between $0-45^{\circ}$ and $1^{\circ}$ above $45^{\circ}$. Volumes were reconstructed using Inspect $3 \mathrm{D}$ v. 3.0 software (FEI Company).

Monitoring pH and calcium concentration in solution. Calcium concentration and $\mathrm{pH}$ were monitored using a calcium-sensitive electrode (Ca-ISE, Metrohm Ltd., Switzerland) and a pH glass electrode (LL Micro glass electrode, Metrohm Ltd.) connected to a TitrandoTM titration device (Metrohm Ltd.) and analysed online using TiamoTM software (Metrohm Ltd.). The Ca-ISE was calibrated by titrating the $10 \mathrm{mM}$ calcium stock to $25 \mathrm{ml}$ tris-buffered saline $(\mathrm{pH}=7.4)$ at room temperature with an addition rate of $0.1 \mathrm{ml} \mathrm{min}^{-1}$ using a Dosino dosing device and measuring the signal (in $\mathrm{mV}$ ) as function of calcium concentration present. During the calibration titration the $\mathrm{pH}$ was kept at 7.4. The $\mathrm{pH}$-electrode was calibrated using buffers at $\mathrm{pH}=4.00, \mathrm{pH}=7.00$ and $\mathrm{pH}=9.00$ (Metrohm Ltd., No. 6.2307.100, No. 6.2307.110, No. 6.2307.120).

Small- and wide-angle $X$-ray scattering. Synchrotron small- and wide-angle scattering experiments were carried out at the $\mu$-Spot beamline at BESSY II ${ }^{47}$. Samples were taken at different time points and contained in a vacuum-sealed quartz capillary with a diameter of $1.5 \mathrm{~mm}$ (Anton Paar, Austria) mounted on a Peltier-element (TCU50, Anton Paar). An energy of $15 \mathrm{keV}(\lambda=0.8266 \AA)$ was selected by a multilayer monochromator. For calibration, synthetic hydroxyapatite (Biorad) was used. 2D scattering patterns were collected using a MarMosaic CCD detector (Mar, Evanston, USA). Radial integration of the 2D scattering patterns with the software Fit2D (A. Hammersley, ESRF, Grenoble, France) gave the 
spherically averaged scattering intensity as a function of the modulus of the scattering vector $Q$, with $Q=4 \cdot \pi \cdot \sin (\theta) / \lambda, 2 \theta$ being the scattering angle and $\lambda$ the wavelength. The resulting profiles were corrected for dark current, primary intensity and sample transmission. An additional background signal resulting from the glass capillary was subtracted.

In situ infrared measurements. Infrared spectra were recorded by taking $1 \mathrm{ml}$ samples from a $25 \mathrm{ml}$ reaction solution using horizontal-attenuated reflection (ATRMaxIITM, PIKE Technologies, USA) employing a ZnSe crystal and a FTIR spectrometer (ExcaliburTM, Varian Inc., USA) equipped with a MCT-detector (500 scans, resolution $2 \mathrm{~cm}^{-1}$ ). The tris-buffered saline background was subtracted using Varian resolutions 4.0 software.

In situ AFM solution preparation. High-purity $\mathrm{Na}_{2} \mathrm{HPO}_{4}$ (99.95\%), $\mathrm{KCl}$ (99.999\%), $\mathrm{NaCl}(99.999 \%)$ and $\mathrm{HCl}(1.043 \mathrm{~N})$ from Sigma-Aldrich, $\mathrm{CaCl}_{2}$ (99.99\%) from Alfa Aesar and ultrapure water $\left(18.2 \mathrm{M} \Omega \mathrm{cm}^{-1}\right)$ were used to prepare stock solutions of $\mathrm{CaCl}_{2}(300 \mathrm{mM}), \mathrm{Na}_{2} \mathrm{HPO}_{4}(19 \mathrm{mM})$ and $\mathrm{NaCl}(2.23 \mathrm{M})$. The $\mathrm{pH}$ of phosphate solutions was adjusted to $7.400 \pm 0.005$ using $\mathrm{HCl}$. All the solutions were filtered through filter membranes (pore size $0.22 \mu \mathrm{m}$, PVDF, AcroDisc LC, PALL) before use. $\mathrm{CaCl}_{2} / \mathrm{NaCl}$ solutions of different concentrations were prepared by dilution from the above-mentioned $\mathrm{CaCl}_{2}$ and $\mathrm{NaCl}$ stock solutions. The supersaturated solutions were made by adding an equal volume of $\mathrm{CaCl}_{2} / \mathrm{NaCl}$ solution to $19 \mathrm{mM} \mathrm{Na}_{2} \mathrm{HPO}_{4}$ solution with ionic strength of $0.0244 \mathrm{M}$. We found that the $\mathrm{pH}$ of the supersaturated solutions was maintained at $7.40 \pm 0.02$ at a phosphate concentration of $9.5 \mathrm{mM}$. We therefore used this concentration in all our nucleation experiments. Supersaturation of ACP, OCP and $\mathrm{AP}$ is defined as

$$
\sigma=\ln \left(\frac{\mathrm{IP}}{K_{\mathrm{sp}}}\right)^{\frac{1}{v}}
$$

where IP is the ionic activity product, expressed using the species stoichiometry, $v$ is the number of growth units in the material and $K_{\mathrm{sp}}$ is the solubility activity product. Speciation calculations were performed using Davies's extended DebyeHückel equation ${ }^{48}$ from mass balance expressions for total calcium and total phosphate with appropriate equilibrium constants by successive approximation for the ionic strength. The solubility activity products of HAP and OCP are $\left(3.0610 \times 10^{-7} \mathrm{M}\right)^{18}$ and $\left(6.8810 \times 10^{-7} \mathrm{M}\right)^{16}$, respectively ${ }^{49,50}$. The solubility product of ACP was calculated from values of $\mathrm{Ca}^{2+}$ free + modelled concentration of phosphate in solution of the spherical aggregates stage with chemistry $\mathrm{Ca}_{2}\left(\mathrm{HPO}_{4}\right)_{3}^{2-}$ where the slope of the $\mathrm{Ca}^{2+}$ free $+\mathrm{pH}$ curve was minimal $(\approx 50 \mathrm{~min})$ to assure as little change in chemistry as possible. This resulted in an average solubility product of $\left(6.04 \times 10^{-4}\right)^{5}$ with a range between $\left(5.23-6.56 \times 10^{-4}\right)^{5}$.

We note that this value of the solubility product is nearly identical to that given in the literature ${ }^{50}$. Consequently, values of $\sigma_{\mathrm{ACP}}$ calculated using this solubility differ only slightly from those obtained using the literature value. For example, at the concentration for which $\sigma_{\mathrm{ACP}}=0.04$, using the literature value of the solubility gives 0.12 instead. As these two values are so similar and because ACP first appears near this solubility limit, we conclude that the value used in the analysis is reasonably accurate.

In situ AFM substrate preparation. The collagen was purchased from Advance Biomatrix Corporation. Branded as Purecol, it is a $3.1 \mathrm{mg} \mathrm{ml}^{-1}, \mathrm{pH} 2$ solution of purified bovine Type I collagen (97\%) and Type III collagen (3\%). Individual experiments were done on a $1 \mathrm{ml}$ scale. Typically, the stock collagen solution was diluted in phosphate buffer $\left(10 \mathrm{mM} \mathrm{Na}_{2} \mathrm{HPO}_{4}, 300 \mathrm{mM} \mathrm{KCl}, \mathrm{pH}=4.0\right)$ to make a working solution with $12 \mu \mathrm{g} \mathrm{ml}^{-1}$ collagen and $200 \mathrm{mM} \mathrm{KCl}$. About $100 \mu \mathrm{l}$ of this solution was then applied to a freshly cleaved mica disc (diameter $9.9 \mathrm{~mm}$, Ted Pella Inc.) and left in contact for $30 \mathrm{~min}$, which is long enough for collagen adsorption onto the substrate. Unadsorbed collagen was then rinsed away with water and the undried substrate was used for the nucleation study.

AFM imaging and measurement of nucleation rates. All in situ nucleation rates were measured by tracking the increase in the number of calcium phosphate nuclei per unit area of surface as a function of time with tapping mode atomic force microscopy (Digital Instruments J scanner, Nanoscope IIIA, Veeco) using hybrid probes consisting of silicon tips on silicon nitride cantilevers (HYDRA rectangular lever, $\mathrm{k}=88 \mathrm{pN} \mathrm{nm}^{-1}$, tip radius $<10 \mathrm{~nm}$; Applied Nanostructures Inc., www.appnano.com). The tapping mode was adopted in these experiments to minimize the forces between the surface and AFM tip. The growth solutions were pumped into the fluid cell at a constant rate of $3 \mathrm{mLh}^{-1}$ at $25^{\circ} \mathrm{C}$, which ensured kinetically limited nucleation conditions for our systems. Measurements were made over a range of supersaturations, and nucleation rates were determined from data collected shortly after the onset of nucleation, where the particle number density exhibited a linear dependence on the elapsed time. Data used in our analyses were typically collected within the first $1-2 \mathrm{~h}$ of each experiment.
In situ AFM: determination of mineral phase. The phases of the minerals at different stages were determined by ex situ FTIR and TEM. The samples were captured by terminating the reaction by switching the fluid pumped through the cell from growth solution to ethanol. The resulting samples were then dispersed in ethanol. A drop of dispersion was put on the surface of carbon-coated copper grids and dried in vacuum. TEM studies were carried out using JEOL 2100 TEM microscopes operated at $200 \mathrm{kV}$. The FTIR spectra were collected using a Varian 3100 FTIR spectrometer in the range of $4,000-400 \mathrm{~cm}^{-1}$ with the resolution of $1 \mathrm{~cm}^{-1}$ by $\mathrm{KBr}$ pellet.

\section{References}

1. Volmer, M. \& Weber, A. Keimbildung in übersättigten Gebilden (Nucleation of supersaturated structures). Z. Phys. Chem. 119, 277-301 (1926).

2. Becker, R. \& Döring, W. Kinetische Behandlung der Keimbildung in übersättigten Dämpfen. Ann. Phys. Berlin 24, 719-752 (1935).

3. Navrotsky, A. Energetic clues to pathways to biomineralization: precursors, clusters, and nanoparticles. Proc. Natl Acad. Sci. USA 101, 12096-12101 (2004).

4. Ostwald, W. Z. Studien über die Bildung und Umwandlung fester Körper. Z. Phys. Chem. 22, 289-330 (1897).

5. ten Wolde, P. R. \& Frenkel, D. Homogeneous nucleation and the Ostwald step rule. Phys. Chem. Chem. Phys. 1, 2191-2196 (1999).

6. Legeros, R. Z. Calcium-phosphate based osteoinductive materials. Chem. Rev. 108, 4742-4753 (2008).

7. Omelon, S. J. \& Grynpas, M. D. Relationships between polyphosphate chemistry, biochemistry and apatite biomineralization. Chem. Rev. 108, 4694-4715 (2008)

8. Mahamid, J., Sharir, A., Addadi, L. \& Weiner, S. Amorphous calcium phosphate is a major component of the forming fin bones of zebrafish: indications for an amorphous precursor phase. Proc. Natl Acad. Sci. USA 105, 12748-12753 (2008)

9. Crane, N. J., Popescu, V., Morris, M. D., Steenhuis, P. \& Ignelzi, Jr M. A. Raman spectroscopic evidence for octacalcium phosphate and other transient mineral species deposited during intramembranous mineralization. Bone 39, 434-442 (2006).

10. Mahamid, J. et al. Mapping amorphous calcium phosphate transformation into crystalline mineral from the cell to the bone in zebrafish fin rays. Proc. Natl Acad. Sci. USA 107, 6316-6321 (2010)

11. Eanes, E. D., Gillessen, I. H. \& Posner, A. S. Intermediate states in the precipitation of hydroxyapatite. Nature 208, 365-367 (1965).

12. Posner, A. S. \& Betts, F. Synthetic amorphous calcium phosphate and its relation to bone mineral structure. Acc. Chem. Res. 8, 273-281 (1975).

13. Bonar, L. C., Roufosse, A. H., Sabine, W. K., Grynpas, M. D. \& Glimcher, M. J. $\mathrm{X}$-ray diffraction studies of the crystallinity of bone mineral in newly synthesized and density fractionated bone. Calcif. Tissue Int. 35, 202-209 (1983).

14. Dey, A. et al. The role of prenucleation clusters in surface-induced calcium phosphate crystallization. Nat. Mater. 9, 1010-1014 (2010).

15. Nudelman, F. et al. The role of collagen in bone apatite formation in the presence of hydroxyapatite nucleation inhibitors. Nat. Mater. 9, 1004-1009 (2010).

16. Onuma, K. \& Ito, A. Cluster growth model for hydroxyapatite. Chem. Mater. 10, 3346-3351 (1998).

17. Wang, L. \& Nancollas, G. H. Calcium orthophosphates: crystallization and dissolution. Chem. Rev. 108, 4628-4669 (2008).

18. Gebauer, D., Völkel, A. \& Cölfen, H. Stable prenucleation calcium carbonate clusters. Science 322, 1819-1822 (2008).

19. Vekilov, P. G. Nucleation. Cryst. Growth Des. 10, 5008-5019 (2010).

20. Erdemir, D., Lee, A. Y. \& Myerson, A. S. Nucleation of crystals from solution: classical and two-step models. Acc. Chem. Res. 42, 621-629 (2009).

21. Pouget, E. M. et al. The initial stages of template-controlled $\mathrm{CaCO} 3$ formation revealed by Cryo-TEM. Science 323, 1455-1458 (2009).

22. Hu, Q. et al. The thermodynamics of calcite nucleation at organic interfaces: classical versus non-classical pathways. Faraday Discuss. 159, 509-523 (2012).

23. Brecevic, L. J. \& Füredi-Milhofer, H. Precipitation of calcium phosphates from electrolyte solutions. II. The formation and transformation of the precipitates. Calcif. Tissue Res. 10, 82-90 (1972).

24. Christoffersen, J., Christoffersen, M. R., Kibalczyc, W. \& Andersen, F. A. A contribution to the understanding of the formation of calcium phosphates. J. Cryst. Growth 94, 767-777 (1989).

25. Posner, A. S., Betts, F. \& Blumenthal, N. C. Role of ATP and Mg in the stabilization of biological and synthetic amorphous calcium phosphates. Calcif. Tissue Int. 22, 208-212 (1976)

26. Kokubo, T., Kim, H. M. \& Kawashita, M. Novel bioactive materials with different mechanical properties. Biomaterials 24, 2161-2175 (2003).

27. Terpstra, R. A. \& Bennema, P. Crystal morphology of octacalcium phosphate: theory and observation. J. Cryst. Growth 82, 416-426 (1987). 
28. Kibalzyc, W., Christoffersen, J., Christoffersen, M. R., Zielenkiewicz, A. \& Zielenkiewicz, W. The effect of magnesium ions on the precipitation of calcium phosphates. J. Cryst. Growth 106, 355-366 (1990).

29. Tung, M. S. \& Brown, W. E. An intermediate state in hydrolysis of amorphous calcium phosphate. Calcif. Tissue Int. 35, 783-790 (1983).

30. Kazanci, M., Fratzl, P., Klaushofer, K. \& Paschalis, E. P. Complementary information on in vitro conversion of amorphous calcium phosphate to HA from Raman microspectroscopy and wide angle scattering. Calcif. Tissue Int. 79, 354-359 (2006).

31. Sauer, G. R. \& Wuthier, R. E. Fourier transform infrared characterization of mineral phases formed during induction of mineralization by collagenasereleased matrix vesicles in vitro. J. Biol. Chem. 263, 13718-13724 (1988).

32. Tanford, C. The Hydrophobic Effect (Wiley Interscience, New York, 1973).

33. Besenius, P. et al. Controlling the growth and shape of chiral supramolecular polymers in water. Proc. Natl Acad. Sci. USA 107, 17888-17893 (2010).

34. Weitz, D. A., Huang, J. S., Lin, M. Y. \& Sung, J. Limits of the fractal dimension for irreversible kinetic aggregation of colloids. Phys. Rev. Lett. 54, 1416-1419 (1985).

35. Cerreta, M. K. \& Berglund, K. A. The structure of aqueous solutions of some dihydrogen orthophosphates by laser Raman spectroscopy. J. Cryst. Growth 84, 577-588 (1987).

36. Dorozhkin, S. V. Amorphous calcium (ortho)phosphates. Acta Biomater. 6, 4457-4475 (2010)

37. Friddle, R. W. et al. Subnanometer atomic force microscopy of peptide-mineral interactions links clustering and competition to acceleration and catastrophe. Proc. Natl. Acad. Sci. USA 107, 11-15 (2010).

38. Nielsen, A. E. \& Söhnel, O. Interfacial tensions electrolyte crystal-aqueous solution, from nucleation data. J. Cryst. Growth 11, 233-242 (1971).

39. Zhang, H., Chen, B. \& Banfield, J. F. The size dependence of the surface free energy of titania nanocrystals. Phys. Chem. Chem. Phys. 11, 2553-2558 (2009).

40. Cheng, X., Xu, L., Patterson, A., Jaeger, H. M. \& Nagel, S. R. Towards the zerosurface-tension limit in granular fingering instability. Nat. Phys. 4, 234-237 (2008).

41. Betts, F. \& Posner, A. S. An X-ray radial distribution study of amorphous calcium phosphate. Mater. Res. Bull. 9, 353-360 (1974).

42. Urch, H., Vallet-Regi, M., Ruiz, L., Gonzalez-Calbet, J. M. \& Epple, M. Calcium phosphate nanoparticles with adjustable dispersability and crystallinity. J. Mater. Chem. 19, 2166-2171 (2009).

43. Wu, Y., Glimcher, M. J., Rey, C. \& Ackerman, J. L. A unique protonated phosphate group in bone mineral not present in synthetic calcium phosphates. Identification by phosphorus-31 solid state NMR spectroscopy. J. Mol. Biol. 244, 423-435 (1994).

44. Demichelis, R., Raiteri, P., Gale, J. D., Quigley, D. \& Gebauer., D. Stable prenucleation mineral clusters are liquid-like ionic polymers. Nat. Commun. 2, 590 (2011).

45. Termine, J. D. \& Posner, A. S. Calcium phosphate formation in vitro. I. Factors affecting initial phase separation. Arch. Biochem. Biophys. 140, 307-317 (1970).

46. Mitchell, D. R. G. DiffTools: electron diffraction software tools for DigitalMicrograph $^{\mathrm{TM}}$. Microsc. Res. Tech. 71, 588-593 (2008).

47. Paris, O. et al. A new experimental station for simultaneous X-ray microbeam scanning for small- and wide-angle scattering and fluorescence at BESSY II. J. Appl. Cryst. 40, s466-s470 (2007).

48. Davies, C. W. Ion Association. 37 (Butterworths, London, 1962).

49. Shyu, L. J., Perez, L., Zawacki, S. J., Heughebaert, J. C. \& Nancollas, G. H. The solubility of octacalcium phosphate at $37^{\circ} \mathrm{C}$ in the system $\mathrm{Ca}(\mathrm{OH}) 2-\mathrm{H}$ 3PO4-KNO3-H2O. J. Dent. Res. 62, 398-400 (1983).

50. Meyer, J. L. \& Eanes, E. D. A thermodynamic analysis of the secondary transition in the spontaneous precipitation of calcium phosphate. Calcif. Tissue Res. 25, 209-216 (1978).
51. Fowler, B. O., Markovic, M. \& Brown, W. E. Octacalcium phosphate. 3. Infrared and Raman vibrational spectra. Chem. Mater. 5, 1417-1423 (1993).

52. Gadaleta, S. J., Paschalis, E. P., Betts, F., Mendelsohn, R. \& Boskey, A. L. Fourier transform infrared spectroscopy of the solution-mediated conversion of amorphous calcium phosphate to hydroxyapatite: new correlations between X-ray diffraction and infrared data. Calcif. Tissue Int. 58, 9-16 (1996).

53. Fratzl, P. Small-angle scattering in materials science-a short review of applications in alloys, ceramics and composite materials. J. Appl. Cryst. 36, 397-404 (2003).

54. Fratzl, P. Small-angle neutron scattering in materials science. PSI Proceed. 97, 113-128 (1997).

55. von Smoluchowski, M. Contribution to the theory of electro-osmosis and related phenomena. Bull. Int. Acad. Sci. Cracovie 184-199 (1903).

56. Dahirel, V. \& Jardat, M. Effective interactions between charged nanoparticles in water: what is left from the DLVO theory? Curr. Opin. Colloid Interface Sci. 15, 2-7 (2010).

57. Groenewold, J. \& Kegel, W. K. Anomalously large equilibrium clusters of colloids. J. Phys. Chem. B 105, 11702-11709 (2001)

58. Stradner, A. et al. Equilibrium cluster formation in concentrated protein solutions and colloids. Nature 432, 492-495 (2004).

59. Denton, A. R. Charge renormalization, effective interactions, and thermodynamics of deionized colloidal suspensions. J. Phys.:Condens. Matter 20, 494230 (2008)

60. Manning, G. S. Counterion condensation theory of attraction between like charges in the absence of multivalent counterions. Eur. Phys. J. E. 34, 132 (2011).

\section{Acknowledgements}

We would like to thank Dr Stefan Siegel and Dr Chenghao Li for the support during the synchrotron measurements at the $\mu$-Spot beamline of the BESSY II synchrotron facility (Helmholtz Zentrum Berlin) and Peter Fratzl for fruitful and inspiring discussions. We also thank Adelheid Elemans-Mehring for help with ICP measurements, Frits Boogaard and Jarno van Roosmalen for their contribution to the 3D reconstructions, and Dr Fabio Nudelman for taking cryo-TEM images and performing LDSEAD. J.J.D. and J.T. acknowledge grant no. DK61673 from the National Institutes of Health. Theoretical analysis was supported by the Office of Science, Office of Basic Energy Sciences of the US Department of Energy under Contract no. DE-AC02-05CH1123. This research was supported by a VICI grant of The Netherlands Organization for Scientific Research (NWO-CW)

\section{Author contributions}

W.J.E.M.H., J.T., J.J.D. and N.A.J.M.S. conceived the study and wrote the manuscript. W.J.E.M.H., J.T., L.J.B., H.F., L.B., A.S.S., A.V., V.D. and P.H.H.B. performed experiments. W.J.E.M.H., J.T., L.J.B., H.F., L.B., A.S.S., A.V., V.D., P.H.H.B., P.M.F., J.L., P.v.d.S., B.A., G.d.W., J.J.D. and N.A.J.M.S. analysed the data.

\section{Additional information}

Supplementary Information accompanies this paper at http://www.nature.com/ naturecommunications

Competing financial interests: The authors declare no competing financial interests.

Reprints and permission information is available online at http://npg.nature.com/ reprintsandpermissions/

How to cite this article: Habraken W.J.E.M. et al. Ion-association complexes unite classical and non-classical theories for the biomimetic nucleation of calcium phosphate. Nat. Commun. 4:1507 doi: 10.1038/ncomms2490 (2013). 